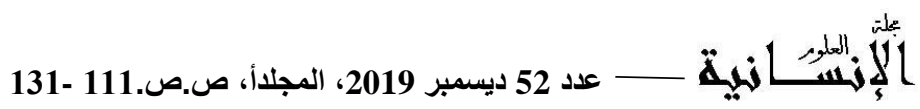

\title{
الروح المعنوية كمتغير وسيط في العلاقة التأثيرية لأبعاد الإرهاب التنظيمي على الاحتراق الوظيفي العلافه التئي
}

Morale as an Intermediate Variant in the Influential Relationship of the Dimensions of Organizational Terrorism to Functional Combustion

تاريخ الاستلام : 2019/04/08 ؛ تاريخ القبول : 2019/09/17

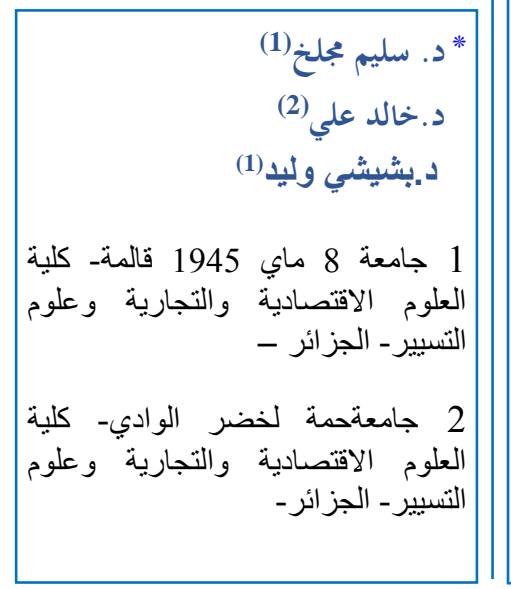

\section{Abstract}

Our research aims to study the effects of the phenomenon of the administrative terrorism as a well spread phenomenon in the Algerian firms and companies on the functional combustion among the workers, because it reduces their profitability and their love to work . we did our practical study in Bir Ater phosphate' $s$ mine which is an old public company and it contains a large number of workers .we gave the survey sheet to some of them . it indicates the the morals of the workers is very low and thus effects their relation with the administration and leads to their Functional Combustion

Keywords: Burned out, organizational terrorism, Morale.

\section{Résumé}

Notre recherche vise à étudier les effets du phénomène du terrorisme administratif en tant que phénomène bien répandu dans les entreprises algériennes et les entreprises sur la combustion fonctionnelle chez les travailleurs, car cela réduit leur rentabilité et leur amour du travail. nous avons effectué notre étude pratique à la mine de Bir Ater Phosphate qui est une ancienne société publique et qui compte un grand nombre de travailleurs. Nous avons donné le questionnaire à certains d'entre eux. il indique que la morale des ouvriers est très basse et affecte ainsi leur relation avec l'administration et conduit à leur combustion fonctionnelle

Mots clés: épuisement professionnel, terrorisme organisationnel, moral.

*Corresponding author, e-mail: asalim2424@gmail.com 


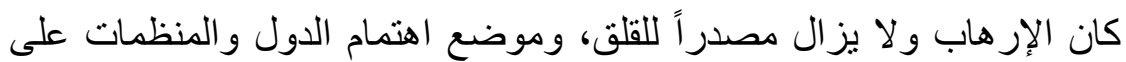

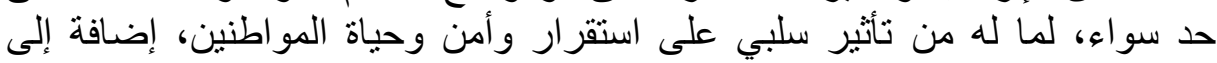

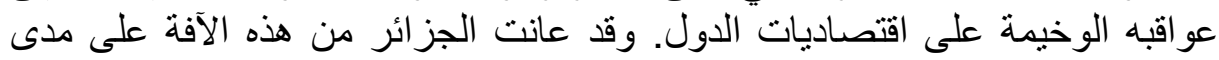

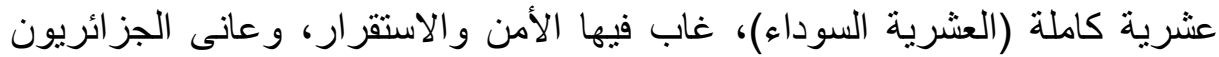

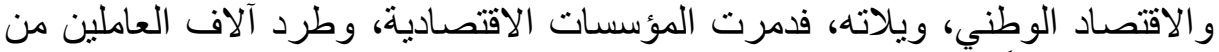

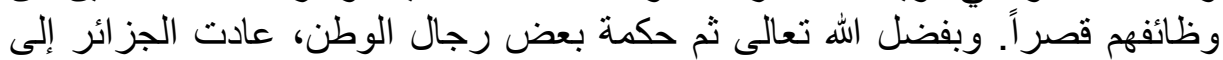

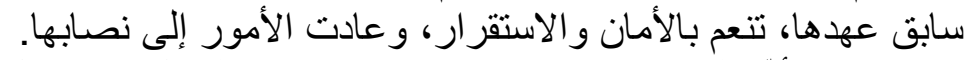

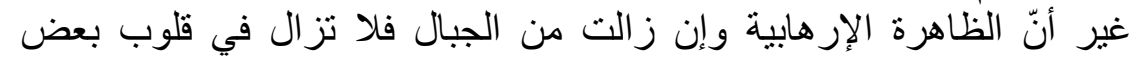

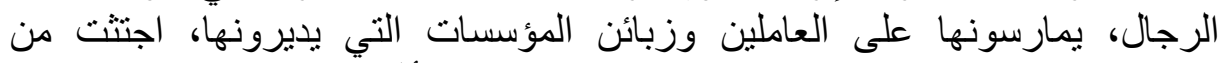

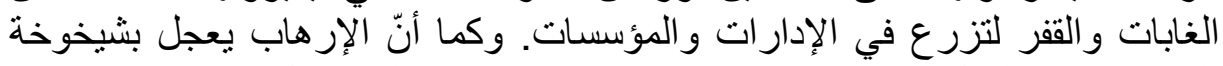

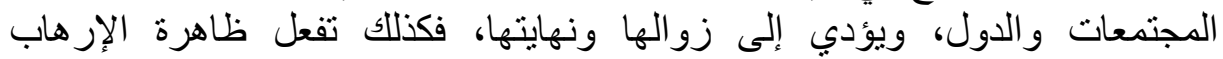

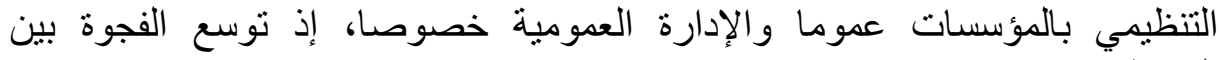

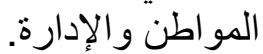
يعتبر المحلل النفسي الأمريكي هربرت فردنبرجر أول من أدخل مصطلح الاحتراق

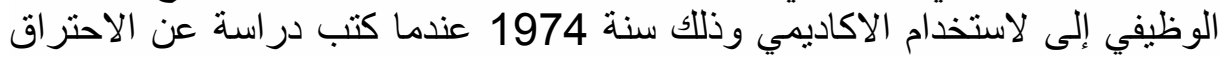

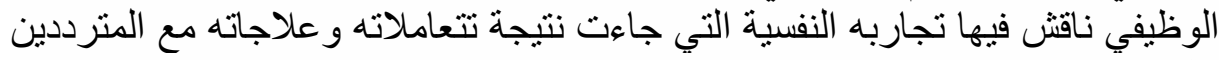

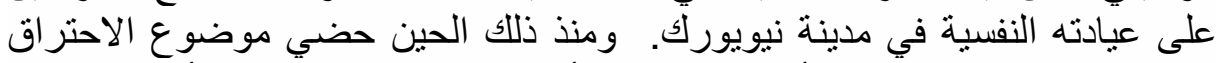

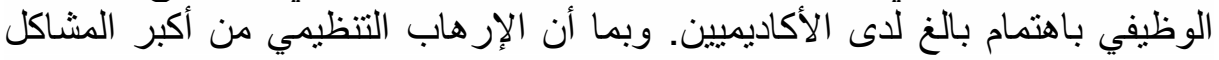

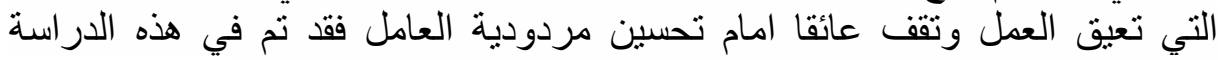

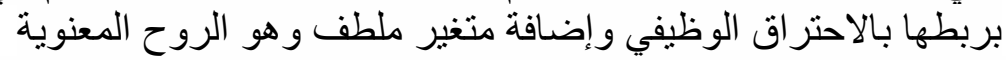
و الروح المعنوية هي وسيلة لتحويل الضعف إلى إلى قوة (الحالة العقلية و النفسية للفرد في

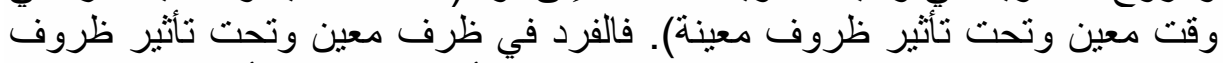

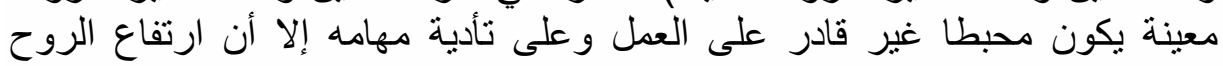

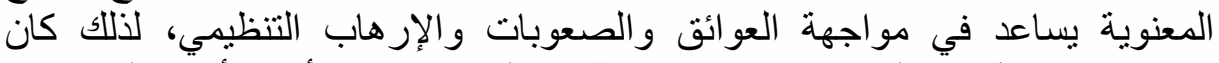

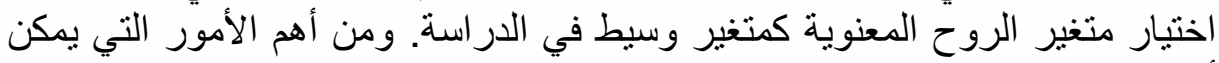

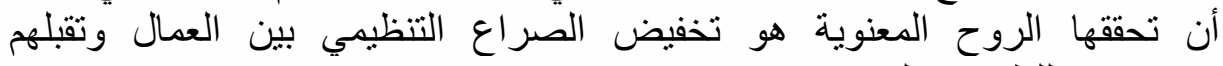
ومواجتهم للظروف المتغيرة

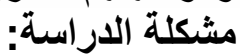

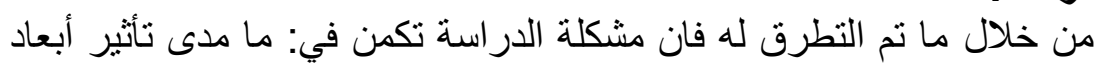

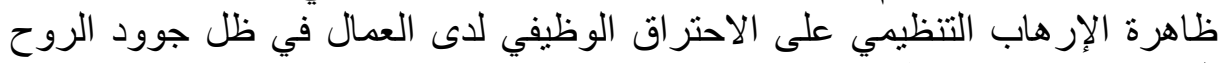

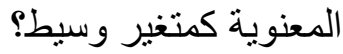

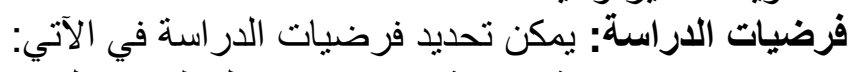

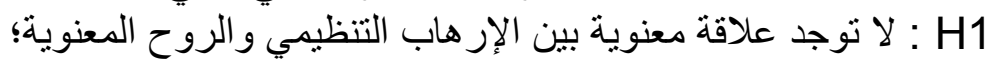

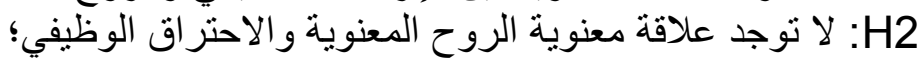
H3

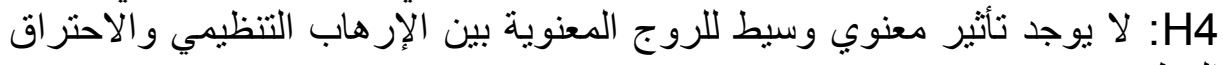

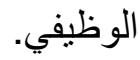
H5 : مسنوى الروح المعنوية ضعيف لدى العمال في المؤسسة قيد الدراسة

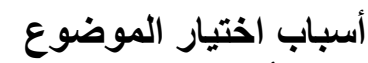
أذكر انه عندما تخرجت في مرحلة اللسانس اردت ان أتقدم للعمل في المركب 
المنجمي للفوسفاط واقترحت ذلك على و الدي فقال لي ان تبقى بطالا على ان تعمل في

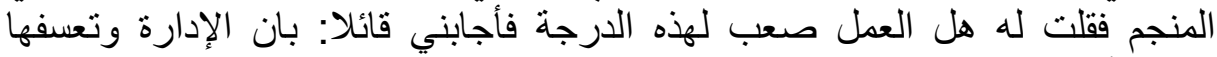
يقتلان أكثر من التعب الجسدي، وبقية هذه العبارة عالقة في ذهني. الامر فانئ الذي الذي دفعني

$$
\text { أولا: القسم النظري }
$$$$
\text { الى الخوض في هذه الدر اسنة. }
$$

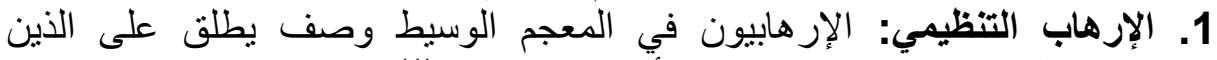

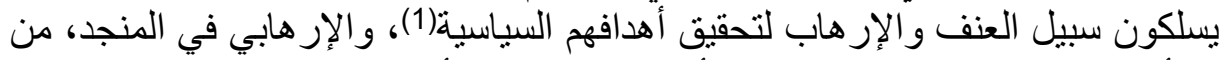

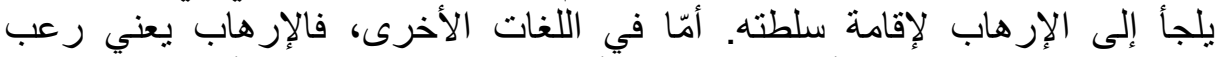
(terror)

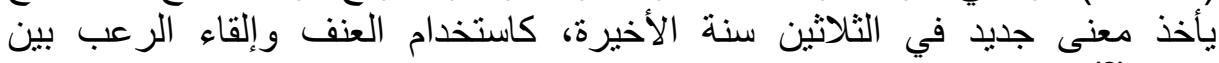

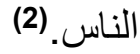

ويرى ريتش (Reich, 1998) بأنّ الإرهاب أمر منطقي واستراتيجية

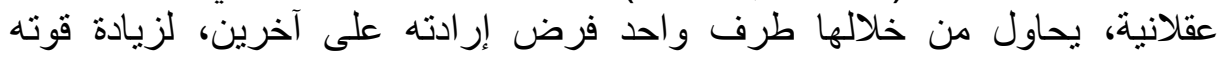

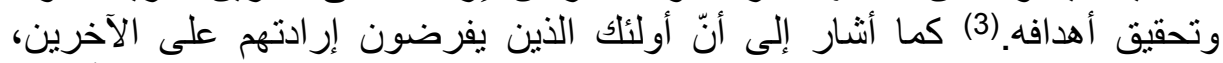

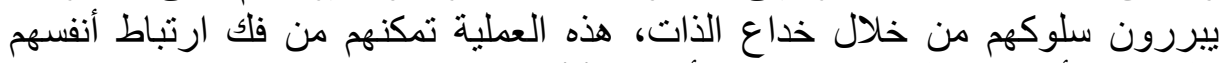

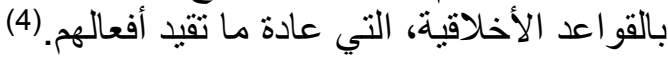

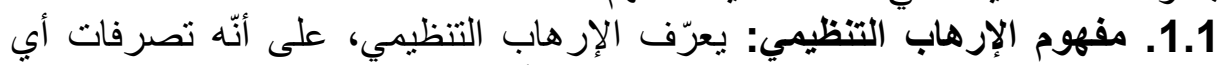

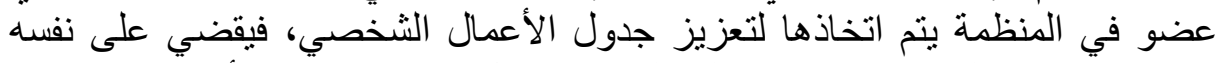

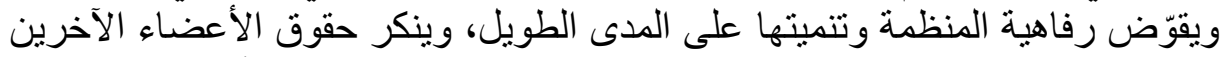

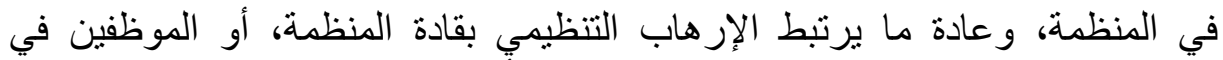

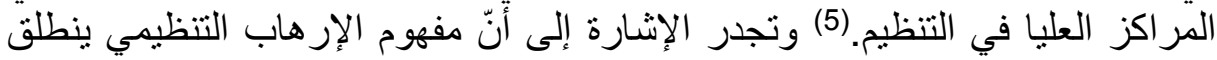

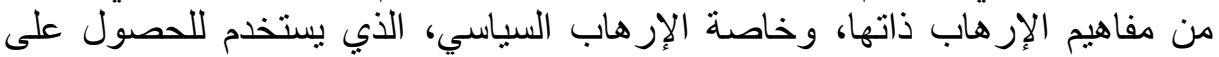

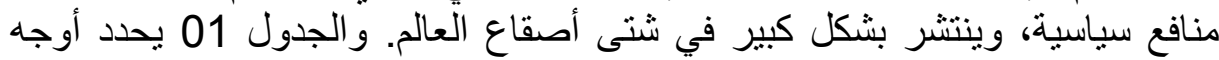
التشابه بين الإرهاب السياسي و الإرهاب التنظيمي.

\begin{tabular}{|c|c|c|}
\hline الإرهاب التنظيمي & الإرهابيون السياسيون & عامل الإرهاب \\
\hline 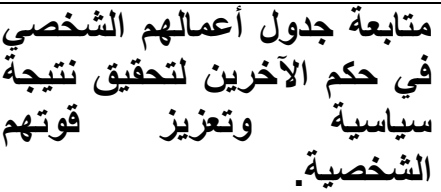 & 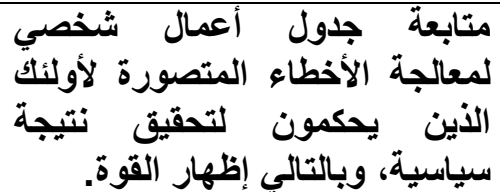 & هدف مدرك \\
\hline 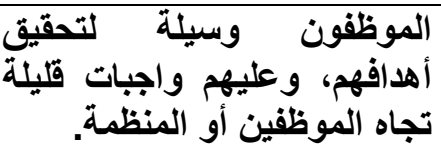 & 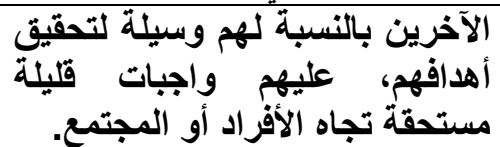 & الآخرين \\
\hline 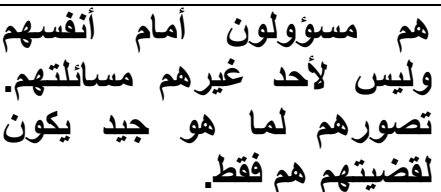 & 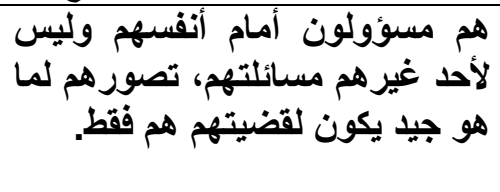 & المسائلة \\
\hline 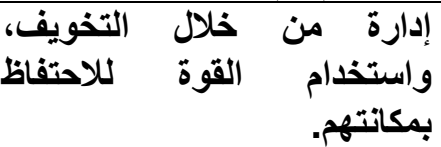 & واستخاذ إجراءات القوة باستخدام التخويف، لإصدار & التهديدات الخدام \\
\hline 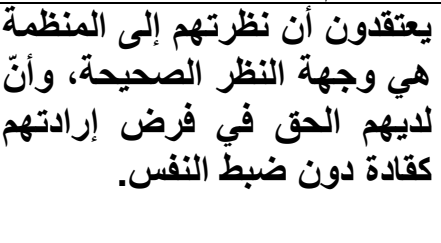 & 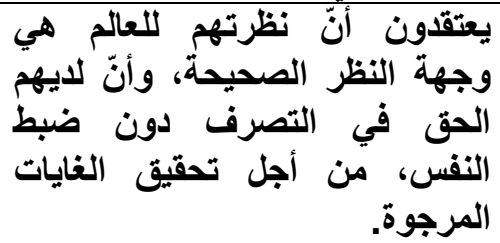 & بالاستحقاق \\
\hline
\end{tabular}




\begin{tabular}{|c|c|c|}
\hline 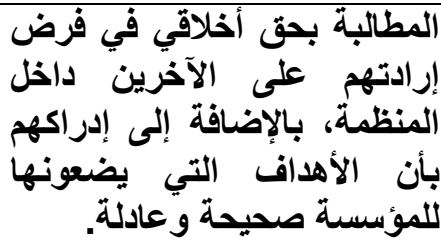 & 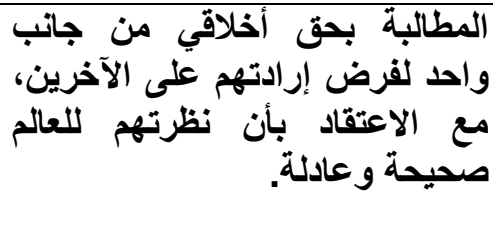 & أخلاقي \\
\hline 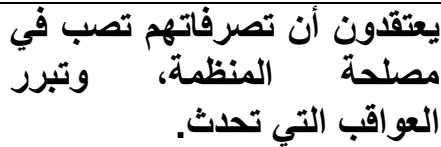 & 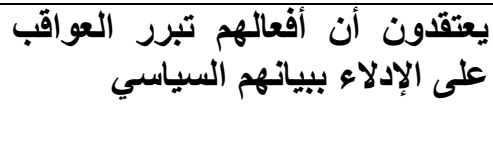 & الإجراءات \\
\hline
\end{tabular}

المصدر: Cam Caldwell, "Organizational Terrorism" and Moral

Choices - Exercising Voice When the Leader is the Problem, Journal of Business Ethics, (2010) 97, p.161.

يوضتح الجدول 01 ، أنّ القادة في المنظمات الإرهابية يتصرفون تماما كما

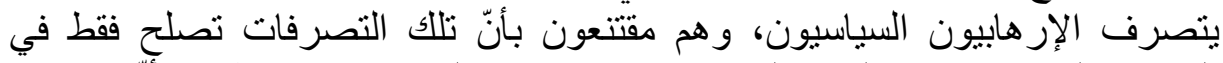

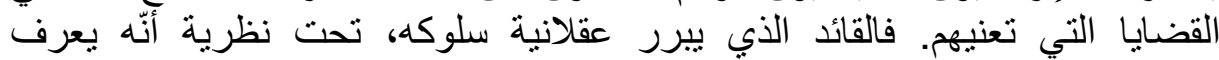

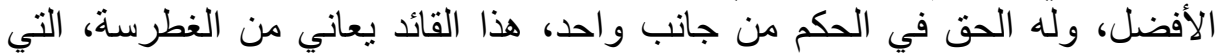

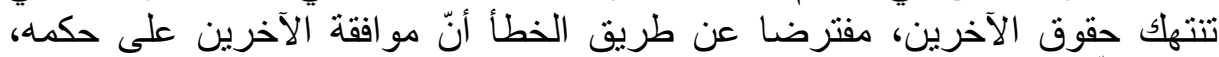

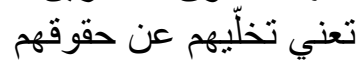
2.1. كيف ينشأ الإرهابي التظيمي:يرى جون دوبين (john dobbin) أنّ الإرهاب

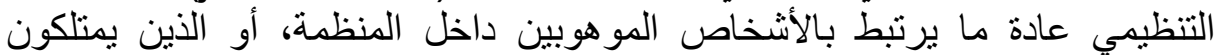

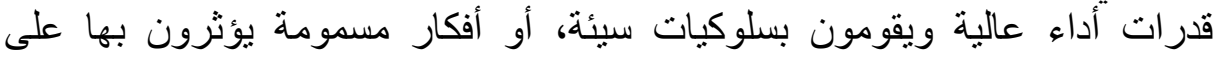

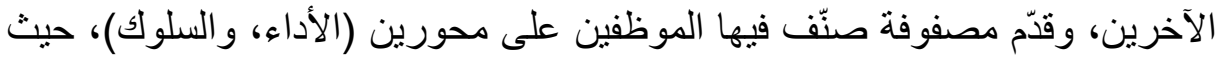
يتعلق الأداء بوظائفه الفنية، ويرتبط السلوك فمدى نجاحهم في التعامل مع الآخرين، و التز امهم بقو انين وأنظمة العمل، والثكل رقم 1 يوضتح كيف يظهر العامل الإرهابي الإين

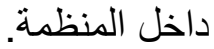

الشكل رقم 1: علاقة الأداء بالسلوك داخل المنظمة، وكيف ينتج العامل الإر هابي.

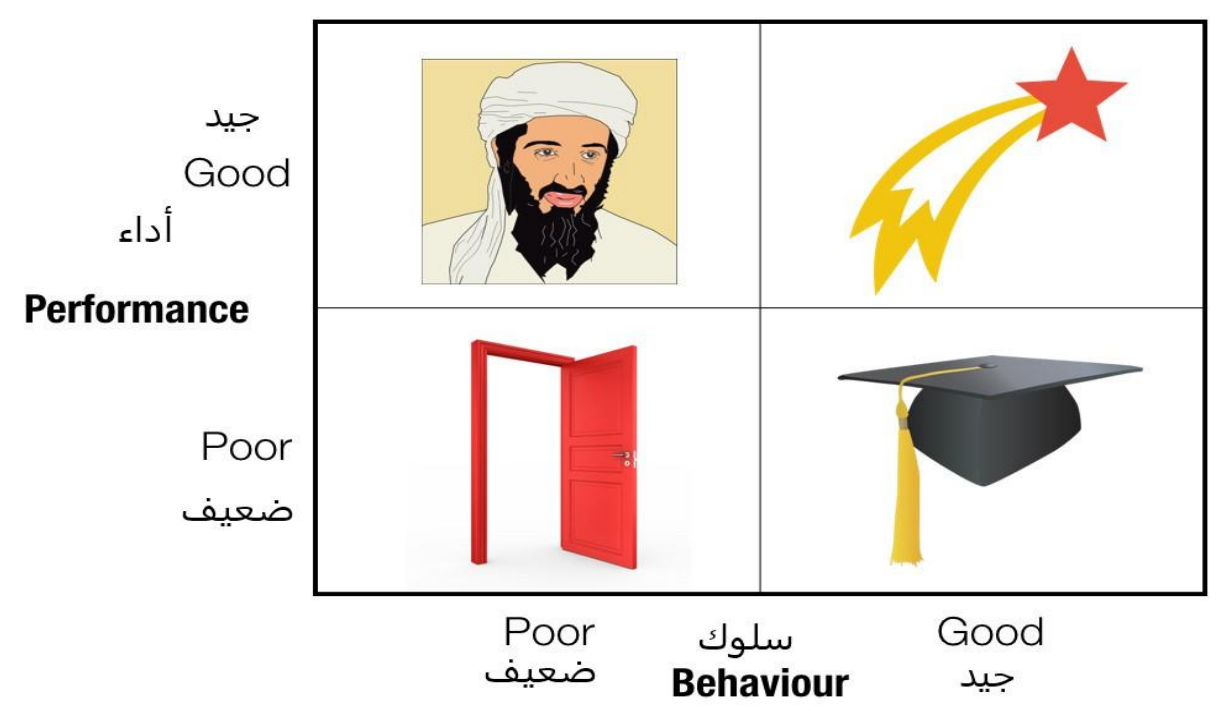

https://www.linkedin.com/pulse/dealing-organisational-2018/01/04 


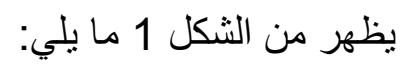

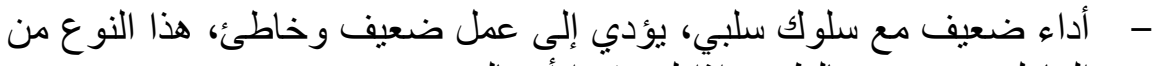

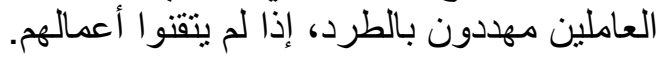

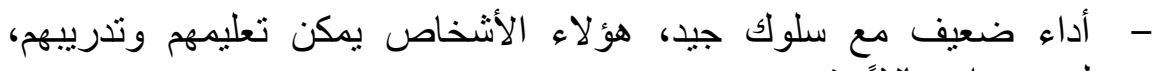
ليصبحو ا عمالا " متميزين.

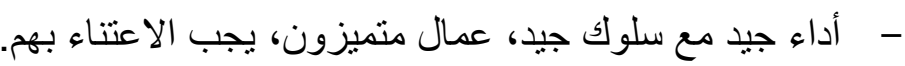

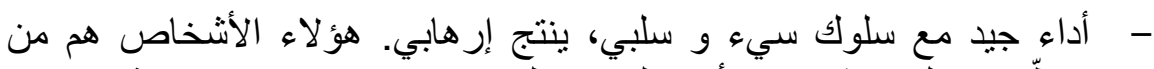

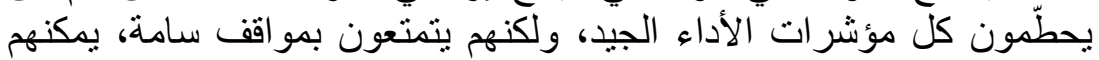

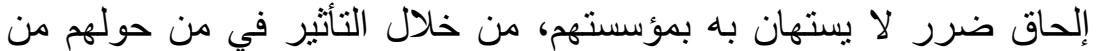

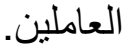

2.1. أقسام الإرهاب التنظيمي: ينقسم الإرهاب التنظيمي إلى أربعة أقسام:(6)

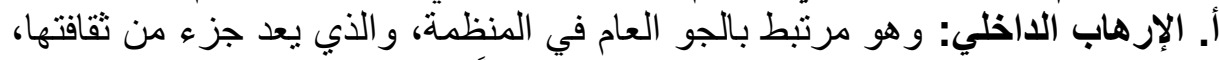

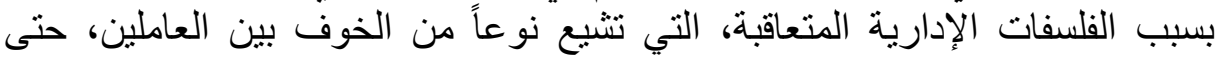

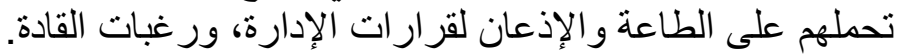

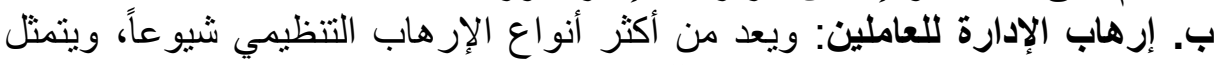

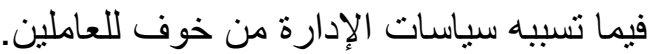

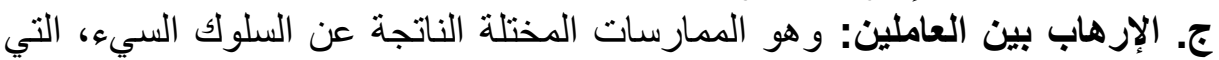

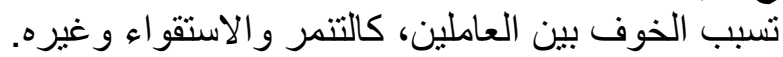

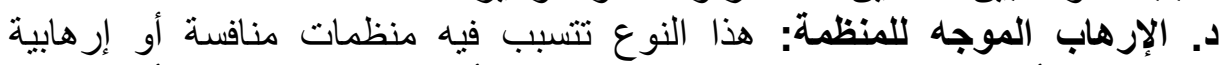

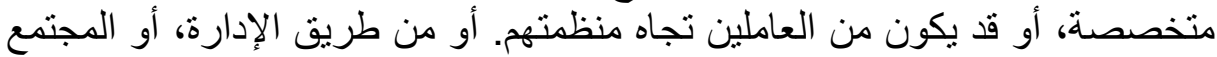
نتيجة تعارض قيم المنظمة مع قيمة فيم المجنمع.

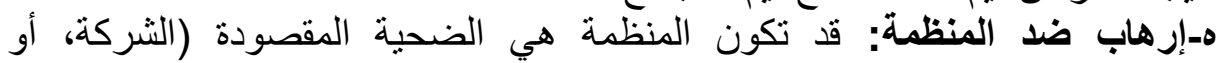

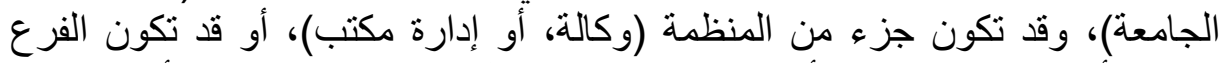

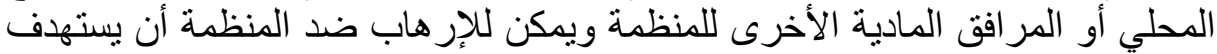

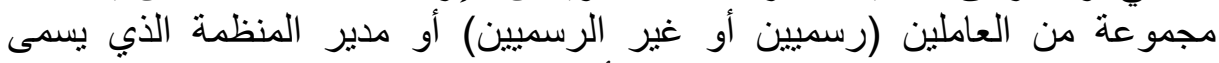

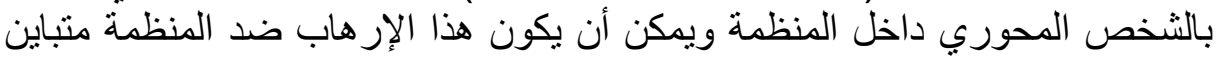

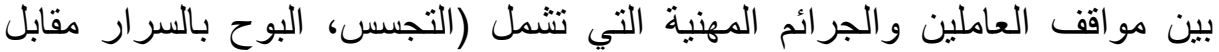
عمو لات مالية، الاحتيال).

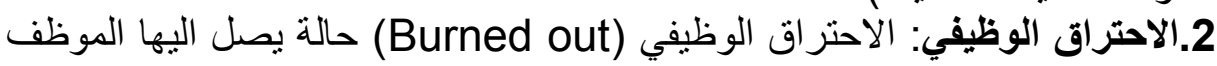

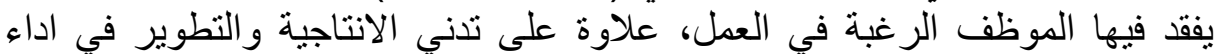

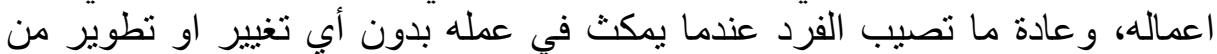

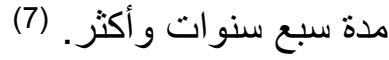
لذلك بادر العديد من الثركات والت والبنوك في الدول الصناعية الى تفادي هذه الحالة قبل حدوثها وذلك بأن تعمل على ان لا يمكث الموظف في عمله اكثر من 5

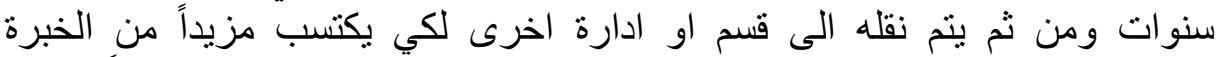

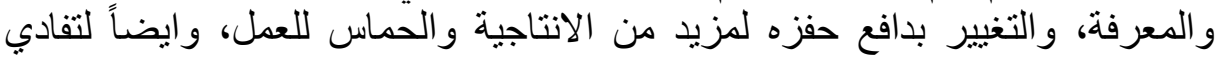

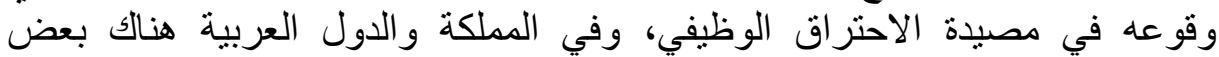

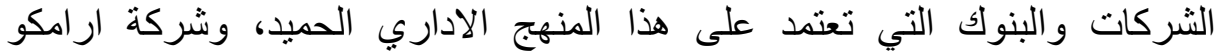
السعودية من ابرز الثركات الرائدة في المنطقة الني تعمل بهذا النئ المنهج الاداري الفي الفعال.

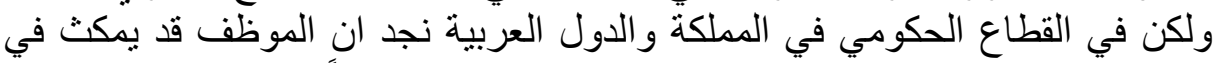

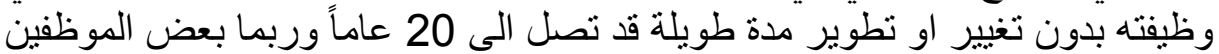

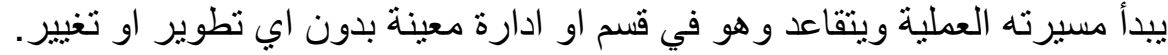

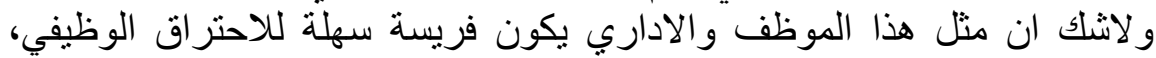

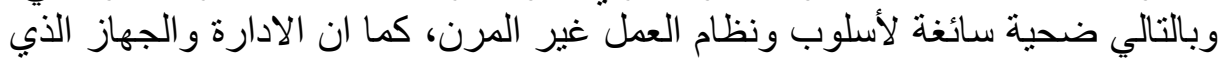


يعمل فيه ضحية ايضاً، لأن أداء وانتاجية الادارة والجهاز الذي يعمل فيه ستكون متدنية جداً بل قد تكون معدومة، مما يؤثر حتماً على انتاجية وكفاءة الجهاء الجهاز الاداري

يعتبر (هربرت فردنيرجر) المحلل الوظيفي الأمريكي أول من أدخل مصطلح ككل.

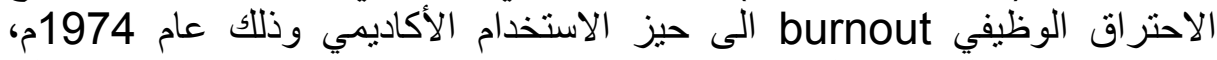

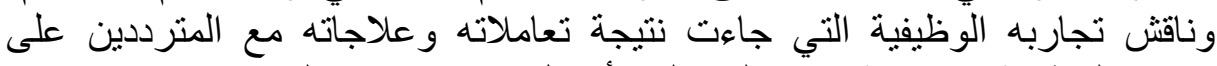

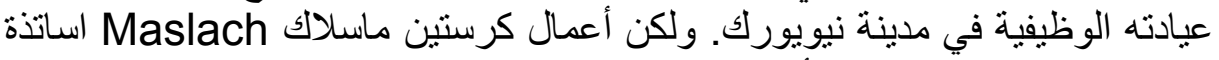

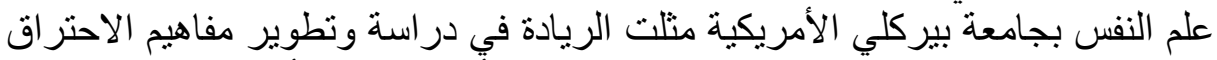

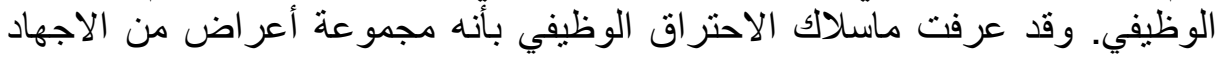

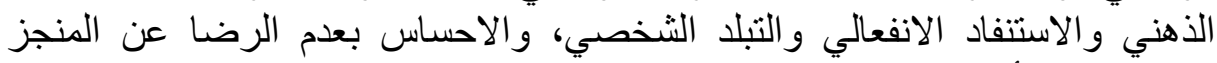

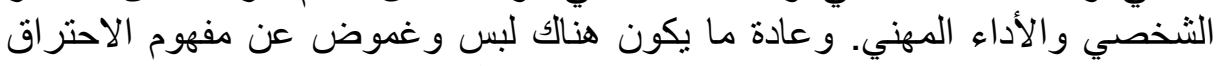

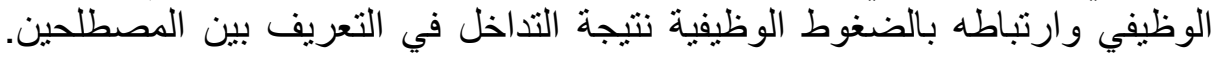

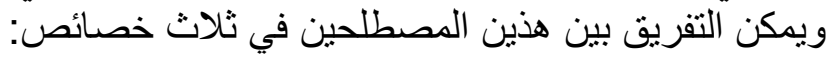

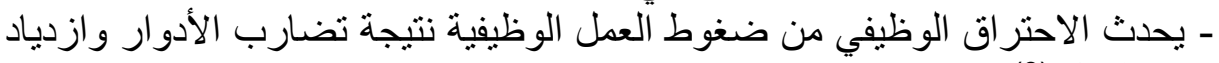
حجم العمل. (8) - يحدث الاحتراق لهؤ لاء الذين عادة ما يتبنون رؤية مثالية لأداء الأعمال والاضطلاع

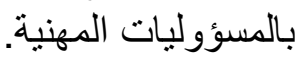

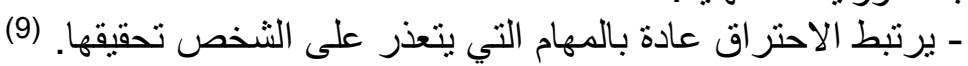

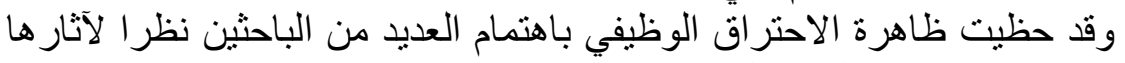

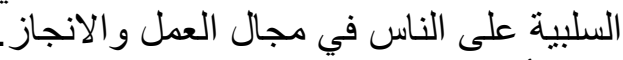

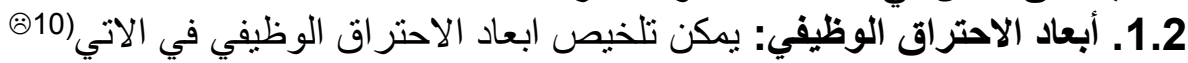

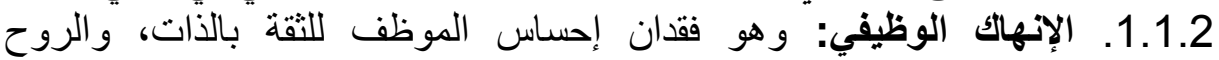

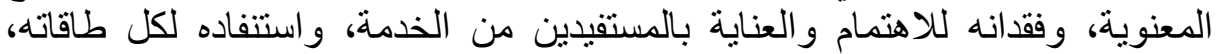

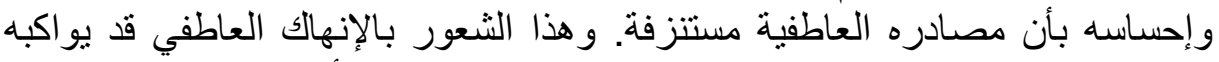

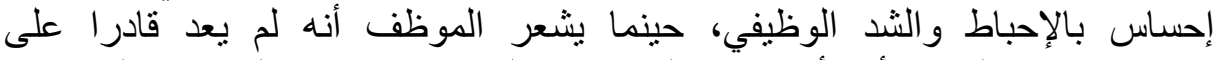

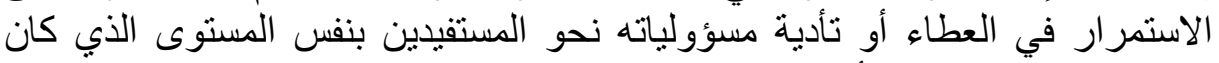

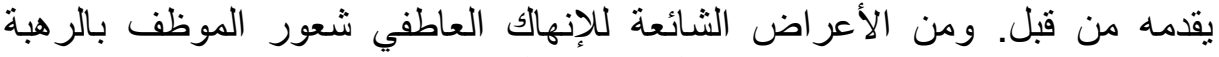

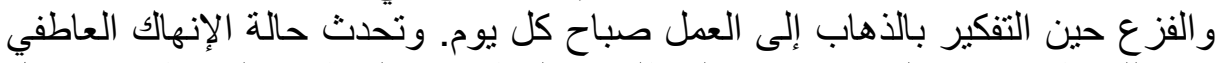
هذه للموظفين في العادة بسبب المتطلبات الوظيفية والعاطفية المفرطة من قبل

2.1.2. الثعور بتدني الإنجاز: ويتسم بميل الموظف إلى تقويم ذاته سلبيا، وشعوره

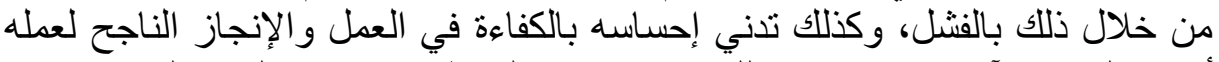

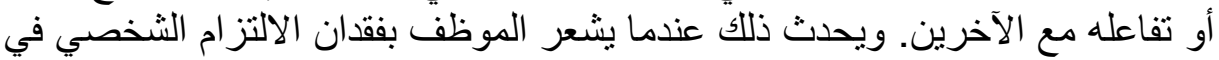

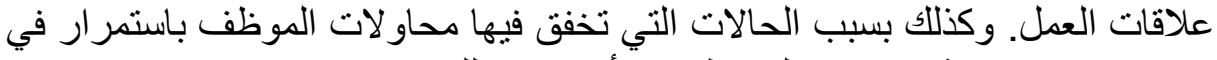

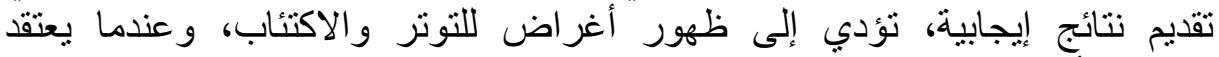

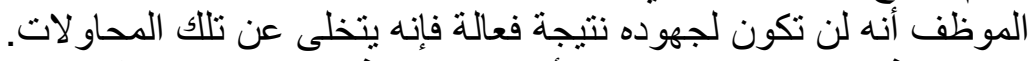

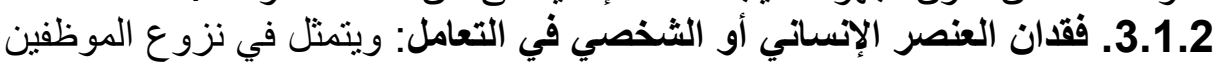

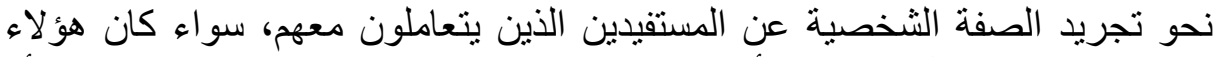

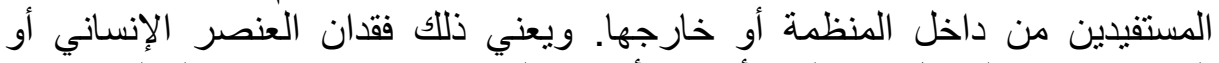

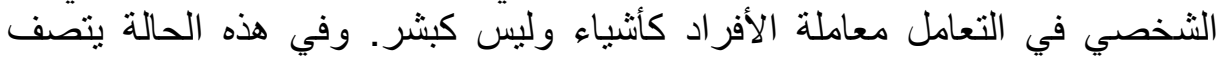

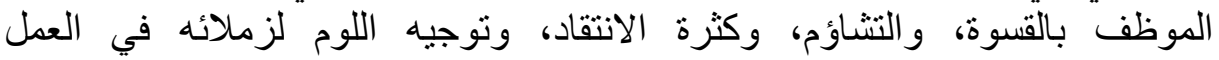

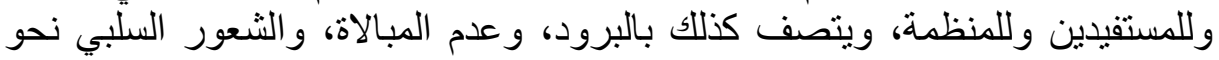

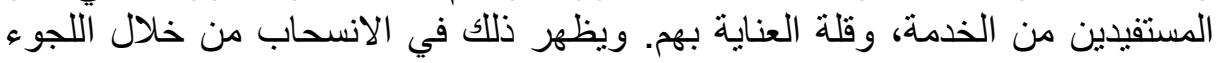


إلى فتر ات طويلة للر احة، أو المحادثات المطولة مع زملاء العمل، أو على الهاتف....

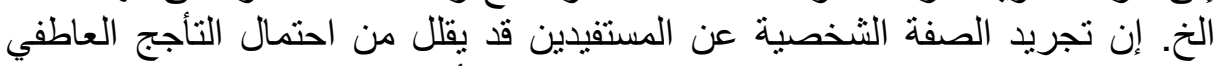

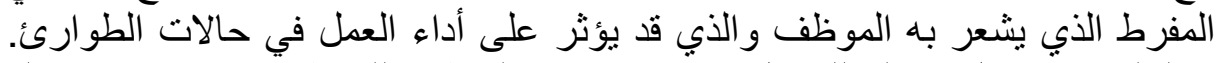

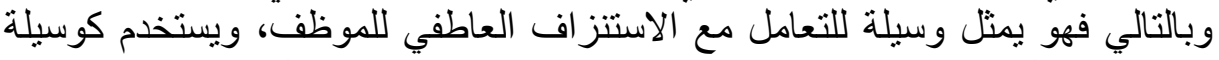

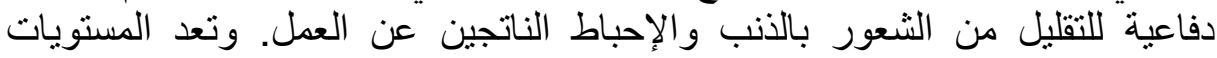
المتوسطة من فقدان العنصر الإنساني أو الثخدصي في الإحساط التعامل مع المستفيدين مناسبة

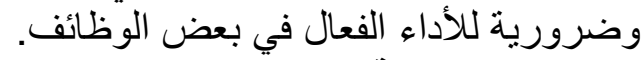

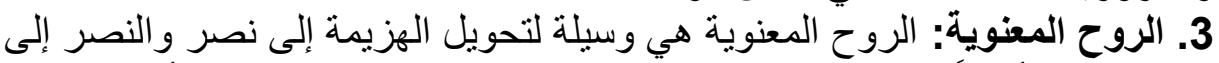

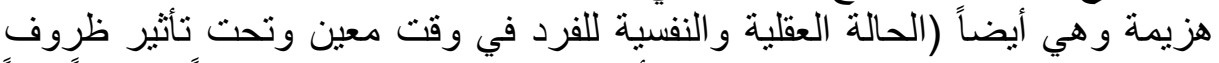

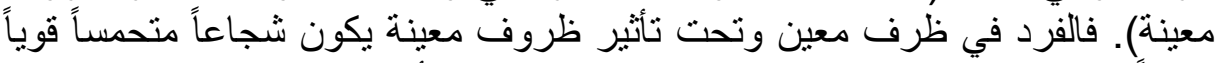

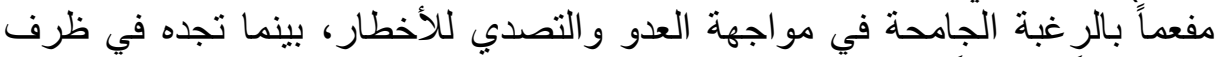

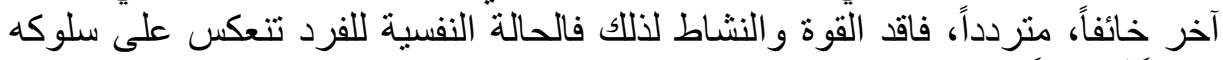
إيجاباً أو سلباً.

كما تعرف الروح المعنوية بأنها (الحالة النفسية الراسخة في أعماق النفس في

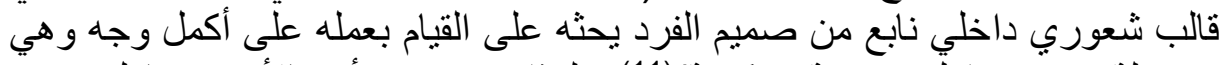

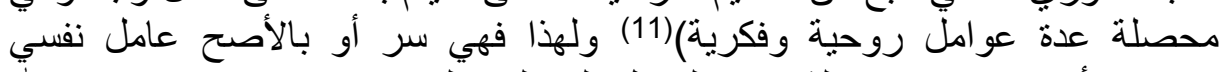

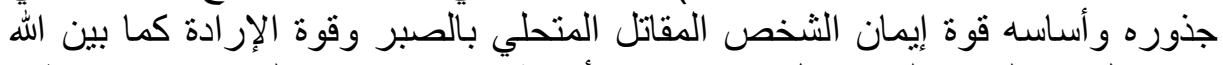

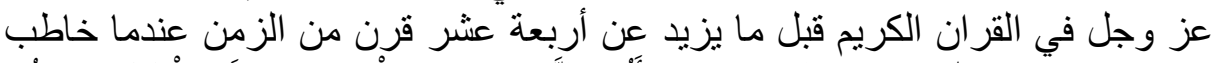

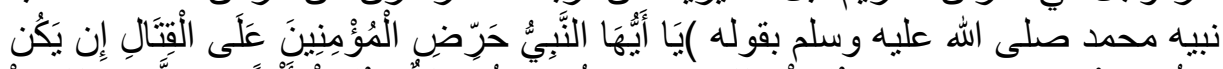

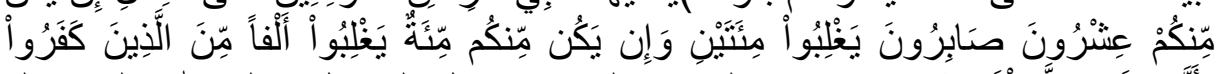

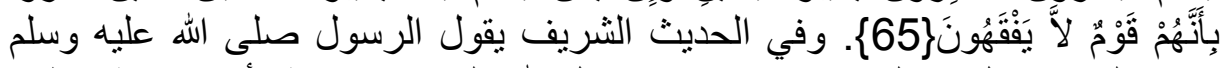
(خير الناس رجل ماسك بعنان فرسه في سبيل الله كلما سمع هيعة (أي صيحة الرس خطر)

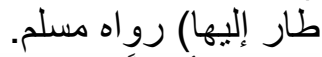
و عرفها أيضاً نابليون : (ليست الطرق التكتيكية هي التي تقرر مصير الحرب و إنما

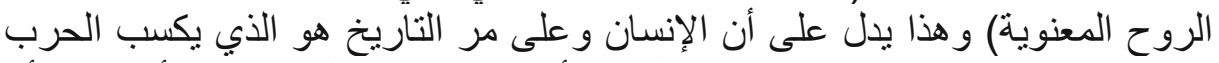

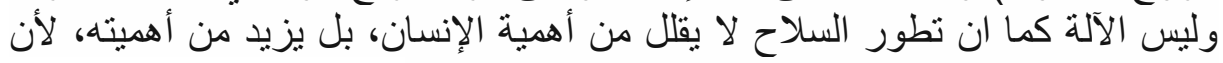

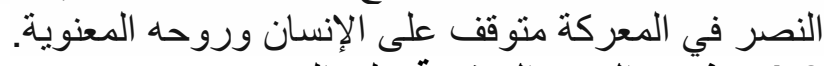

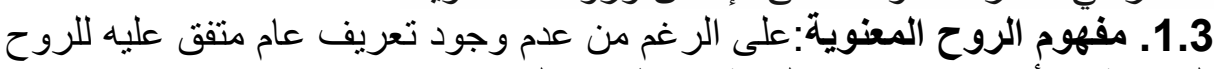

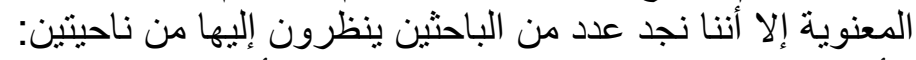

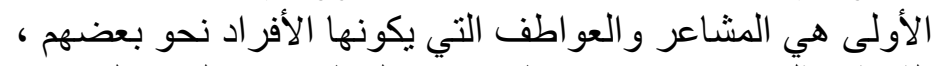

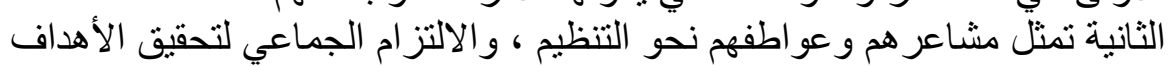
التنظيمية

و على هذا يمكن تعريف الروح المعنوية بأنها : ( الحالة النفسية و الذهنية و العصبية

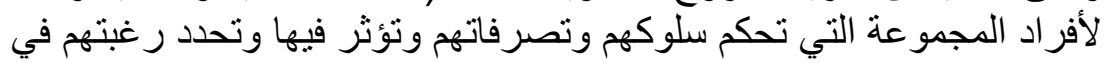
التعاون ). وتعرف الروح المعنوية أيضاً : إنها استعداد أفر اد المجموعة للتعاون فيما بينهم وذلك

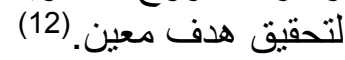

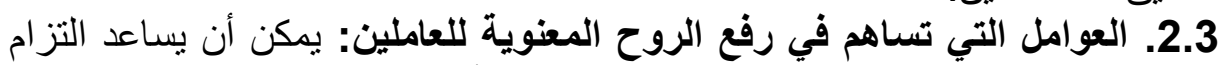

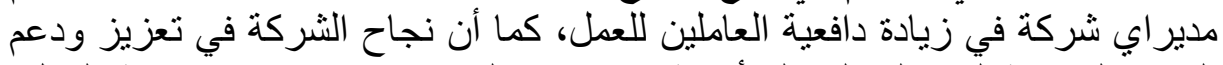

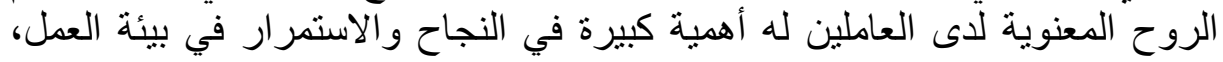

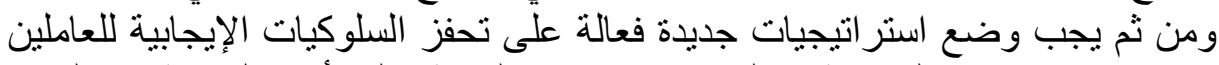

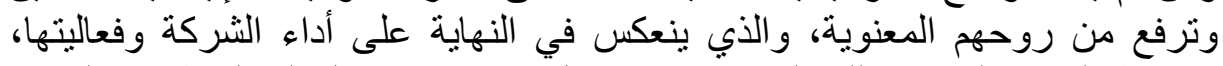

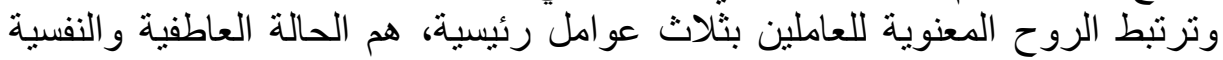

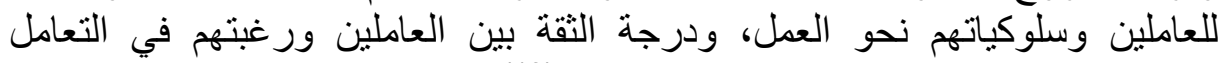
و التكامل بينهم، ودرجة ثقة العاملين في الإدارة. (13) 
ثانيا: الجاتب التطبيقي

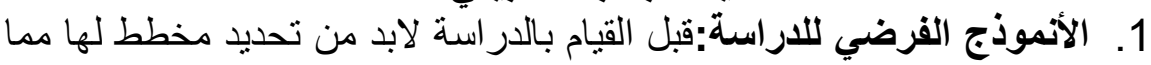

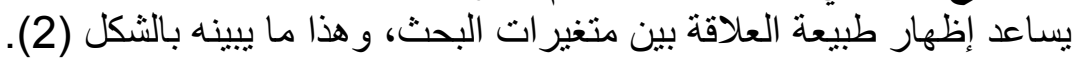

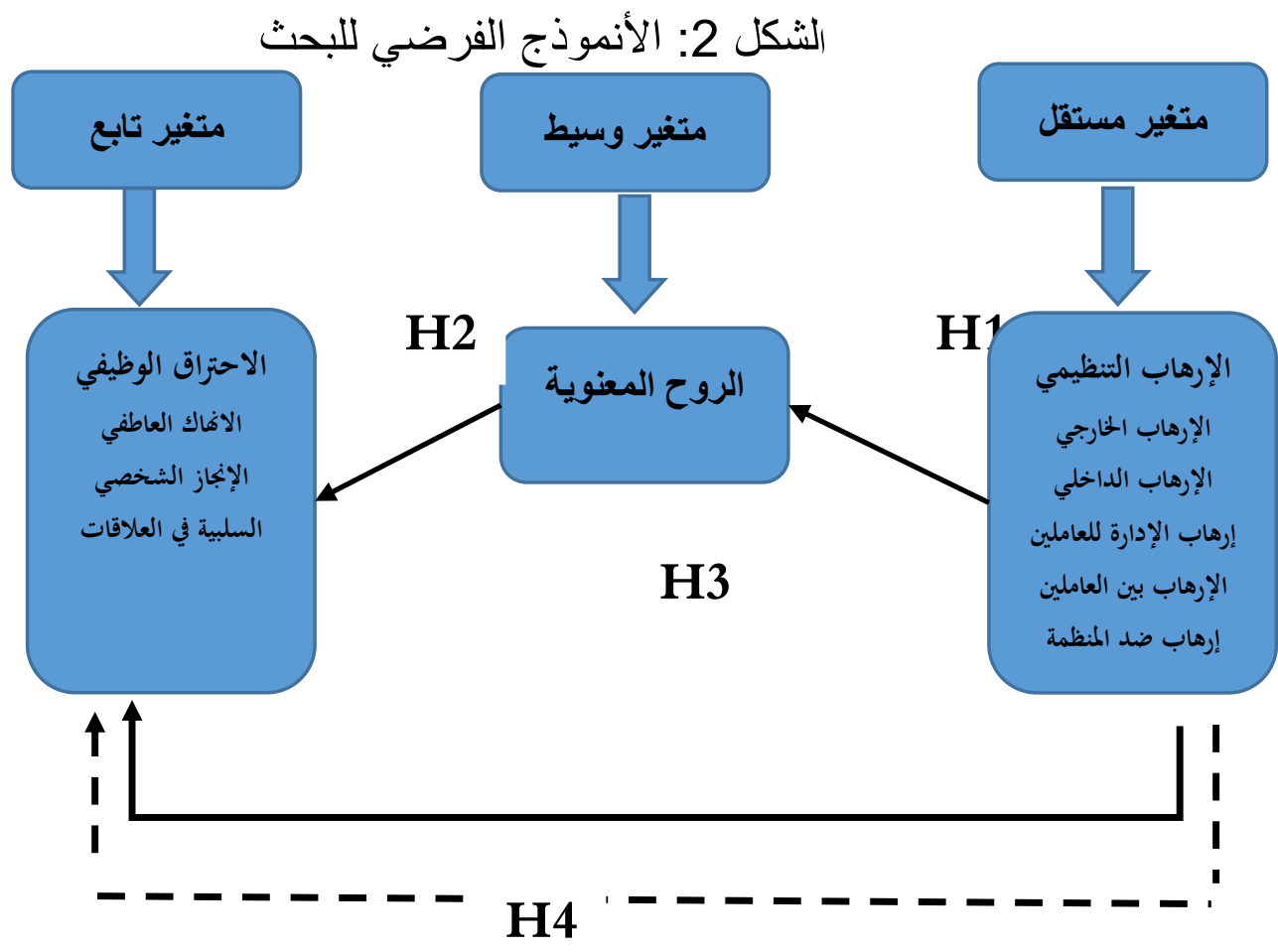

المصدر : من إعداد الباحثين

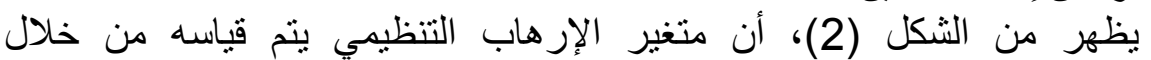

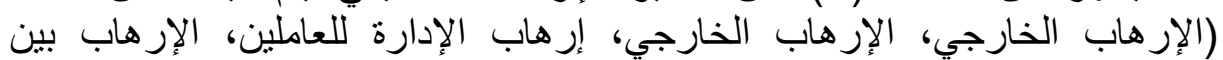

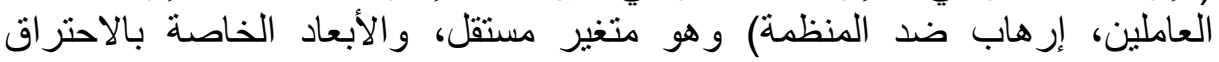
الوظيفي هي (الانهاك العاطفي، الإنجاز الثخصي، التهي، السلبية في العلاقات) يتم اعتمادها في الاحتر اق الوظيفي كمتغير تابع.

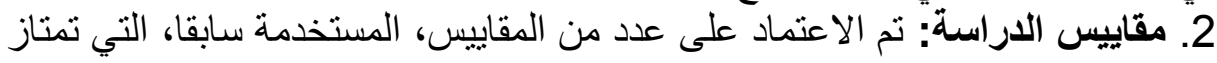

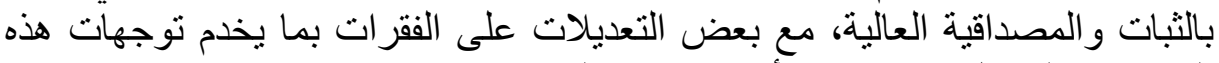

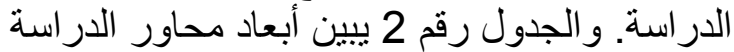

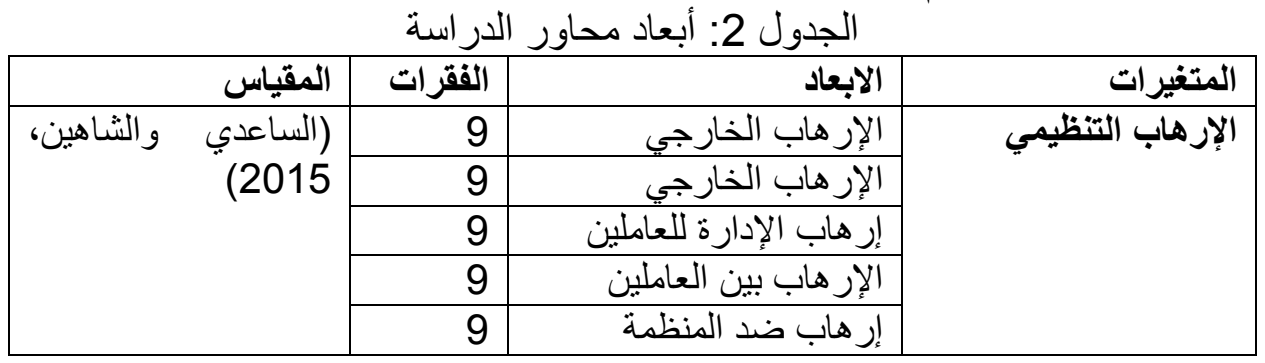


الروح المعنوية كمتغير وسيط في العلاقة التأثيرية لأبعاد الإرهاب التنظبي على الاحتراق الوظيفي

\begin{tabular}{|c|c|c|c|}
\hline & 45 & الاول & \\
\hline \multirow[t]{4}{*}{ (Al Qarni, 2000) } & 9 & الانهاك العاطفي & \multirow[t]{4}{*}{ الاحتراق الوظيفي } \\
\hline & 8 & الإنجاز الشخصي & \\
\hline & 5 & السلبية في العلاقات & \\
\hline & 22 & الثانىوع العبارات للمحور & \\
\hline \multirow[t]{2}{*}{ سها، 2018} & 9 & \multicolumn{2}{|r|}{ الروح المعنوية } \\
\hline & 76 & & المجموع الكلي للاه \\
\hline
\end{tabular}

المصدر: مؤيد يوسف الساعدي ونداء صالح الثناهين، بناء مقياس الإرهاب التنظيمي في

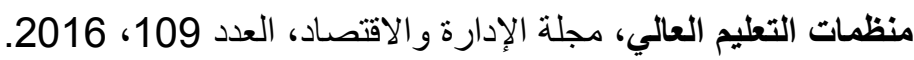

Al Qarni, A. Media and the psychological burnout, a study ofthe 2000..work pressures levels in the media institutes. KSA

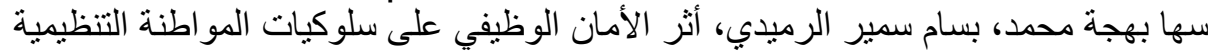

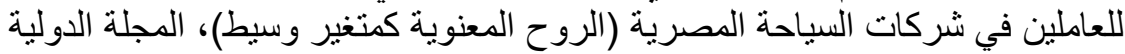

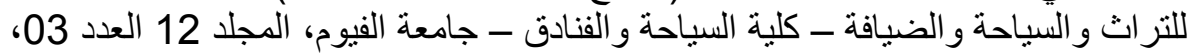
2018

الجدول رقم 2 يبين عدد فقرات المقياس لكل محور. وقد استخدم مقياس ليكرت

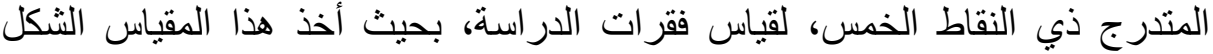

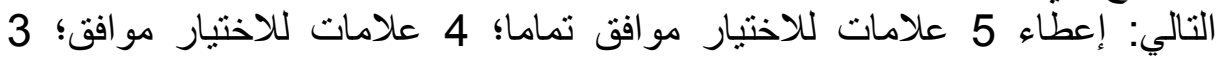

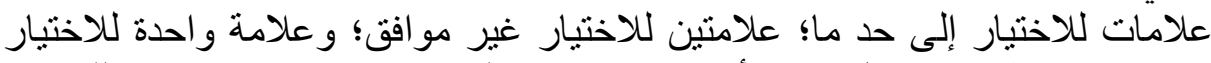

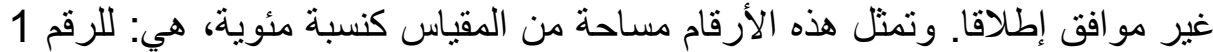

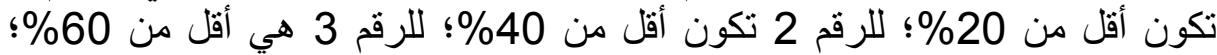

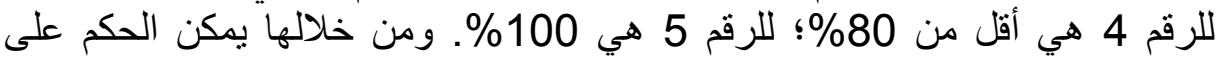

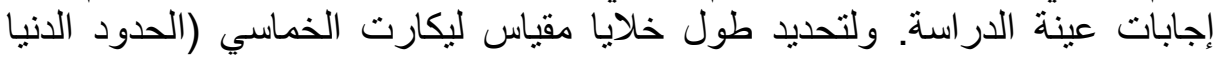

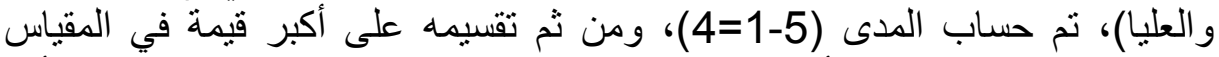

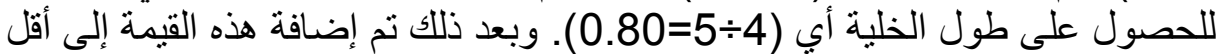

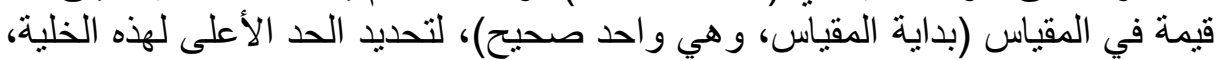

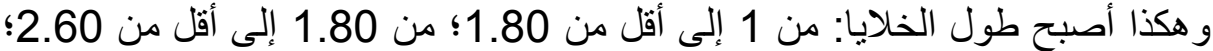

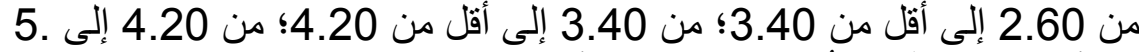

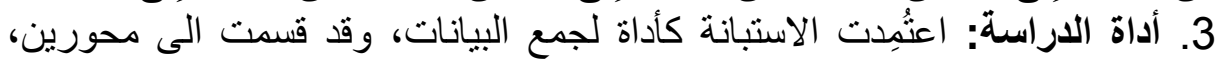

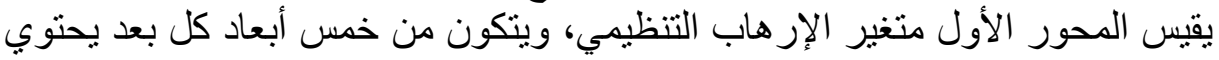
على 9 فقرات بمجموع 45 فقرة للمحور. ويقيس المحور المون الثناني منغير الاحتراق

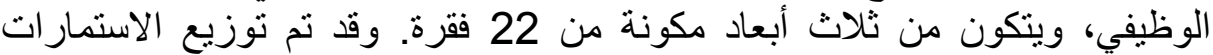

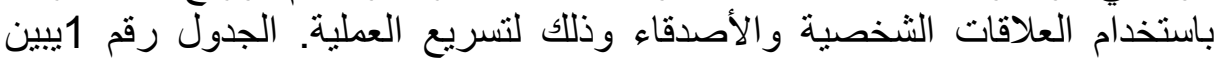
وصف وترميز متغير ات الدر اسة.

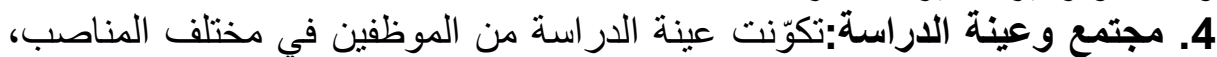

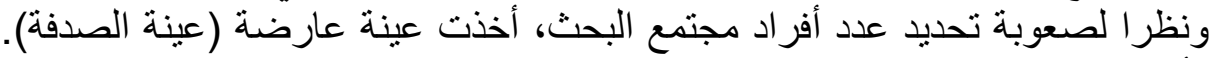

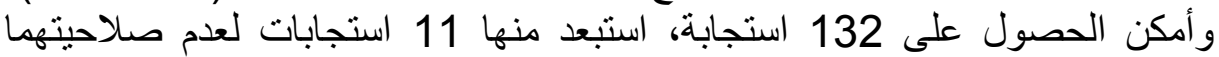

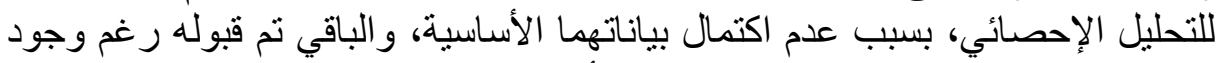

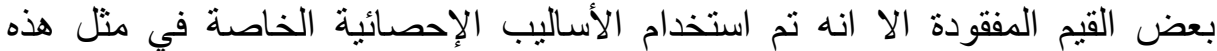

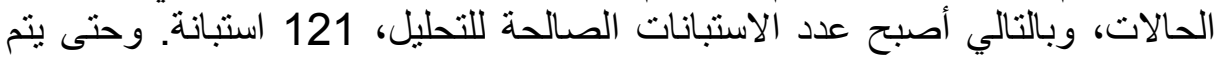

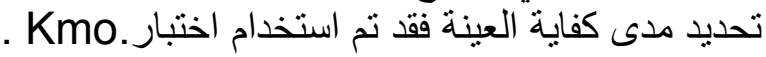


الجدول 3: اختبار KMO الكفاية العينة

\begin{tabular}{|c|c|c|}
\hline & $\begin{array}{l}\text { Kaiser-Meyer-Olkin Measure of Sampling } \\
\text { Adequacy. }\end{array}$ & Sig. \\
\hline المحور الأول & .809 & .000 \\
\hline المحور الثاني & .821 & .000 \\
\hline المحور الثالث & .705 & .000 \\
\hline كامل الاستمارة & .823 & .000 \\
\hline
\end{tabular}

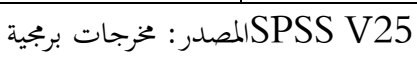

يتبين من الجدول 3 أنّ قيمة اختبار KMOأبي أكبر من الحد الأدنى المقبول لهذا

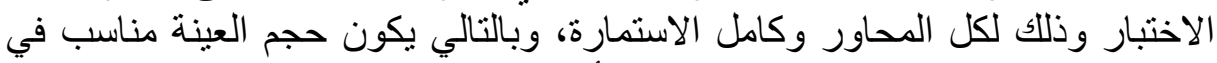

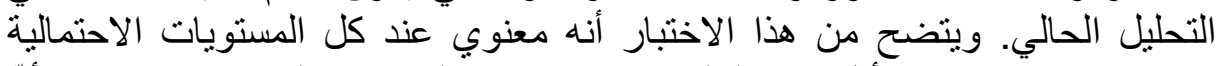

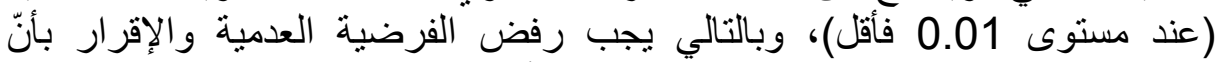

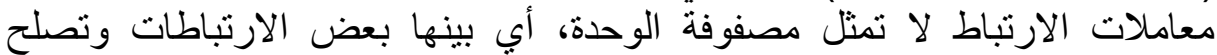

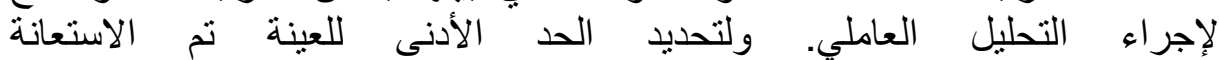

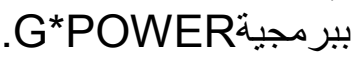

\section{G*POWER الشكل 3: تحديد الحد الأدنى للعينة}

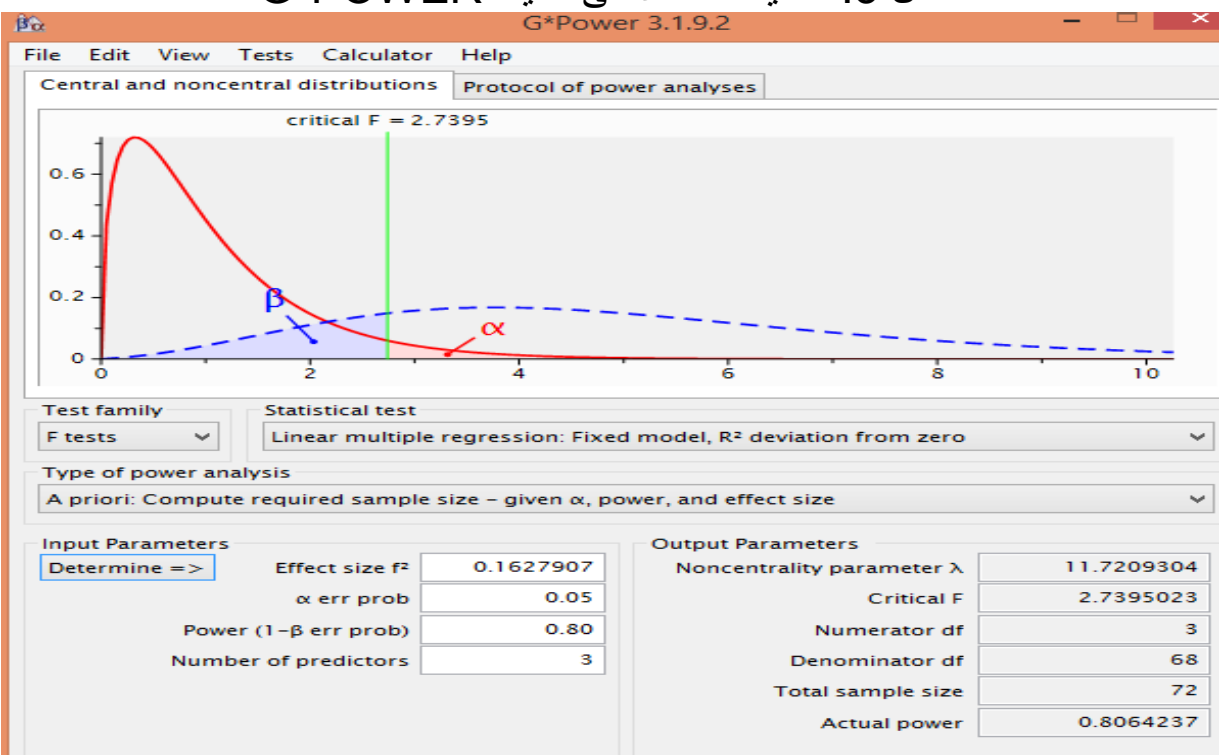

G*POWER المصدر: مخرجات برمجية

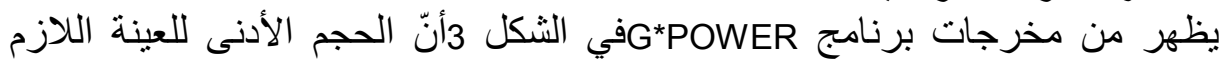
لإجراء الاختبار يساوي 107 مفردة، (total sample size=107)، عند قوة تأثير كبيرة،

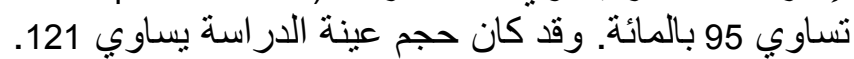

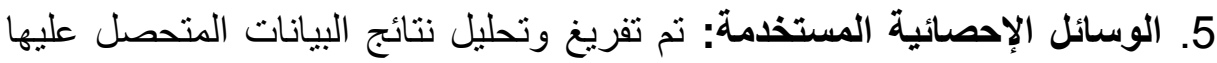

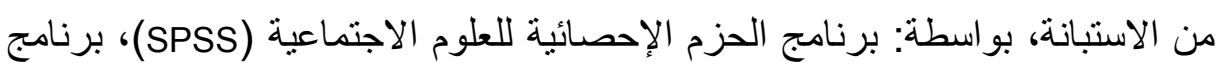

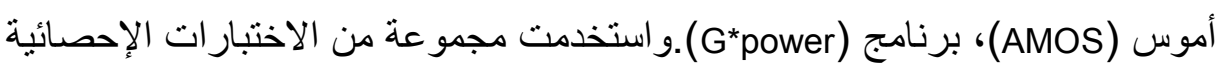
المازمة للادر اسة.

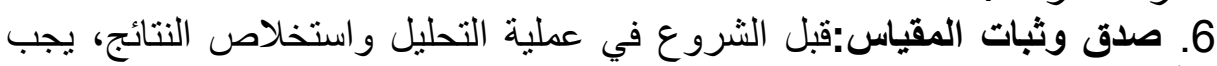
التأكد من مدى صدق وثبات المفات العبار ات التي تضمنتي فئها الاستبانة، حتى تكون النتائج ذات 
مصداقية وأكثر و اقعية. وصدق أداة الدراسة يعني أن تكون الاستبانة شاملة لكل

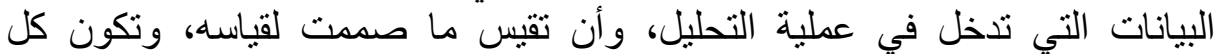

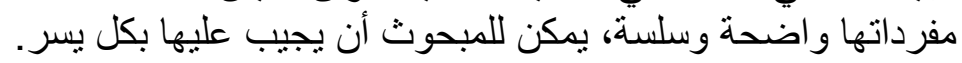

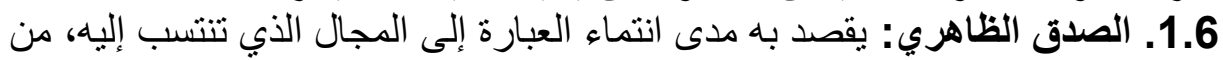

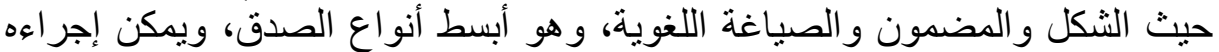
من طرف الباحث نفسه. وفي غالب الأحيان تتم معالجة العبار ات غير العير الصادقة ظاهريا

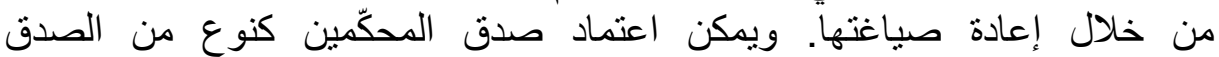

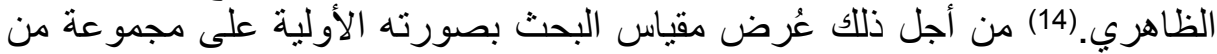

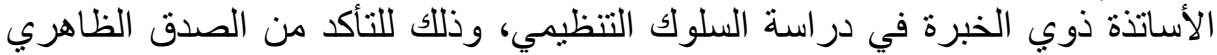

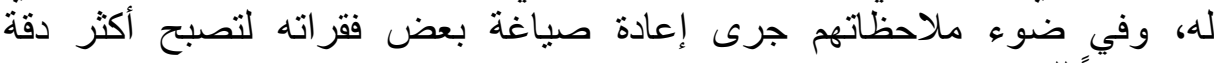
ووضوحا للمستجيبين. 2.6.الصدق البنائي (العاملي): يهتم بتحليل الصفة المقاسة إلى عناصر لمعرفة مدى الصى

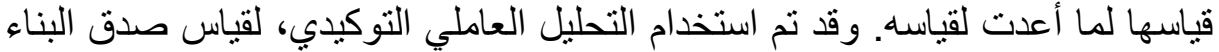

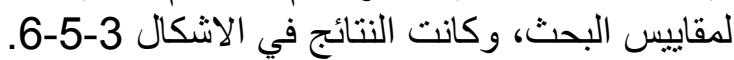

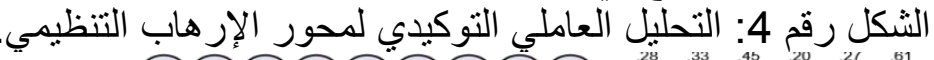

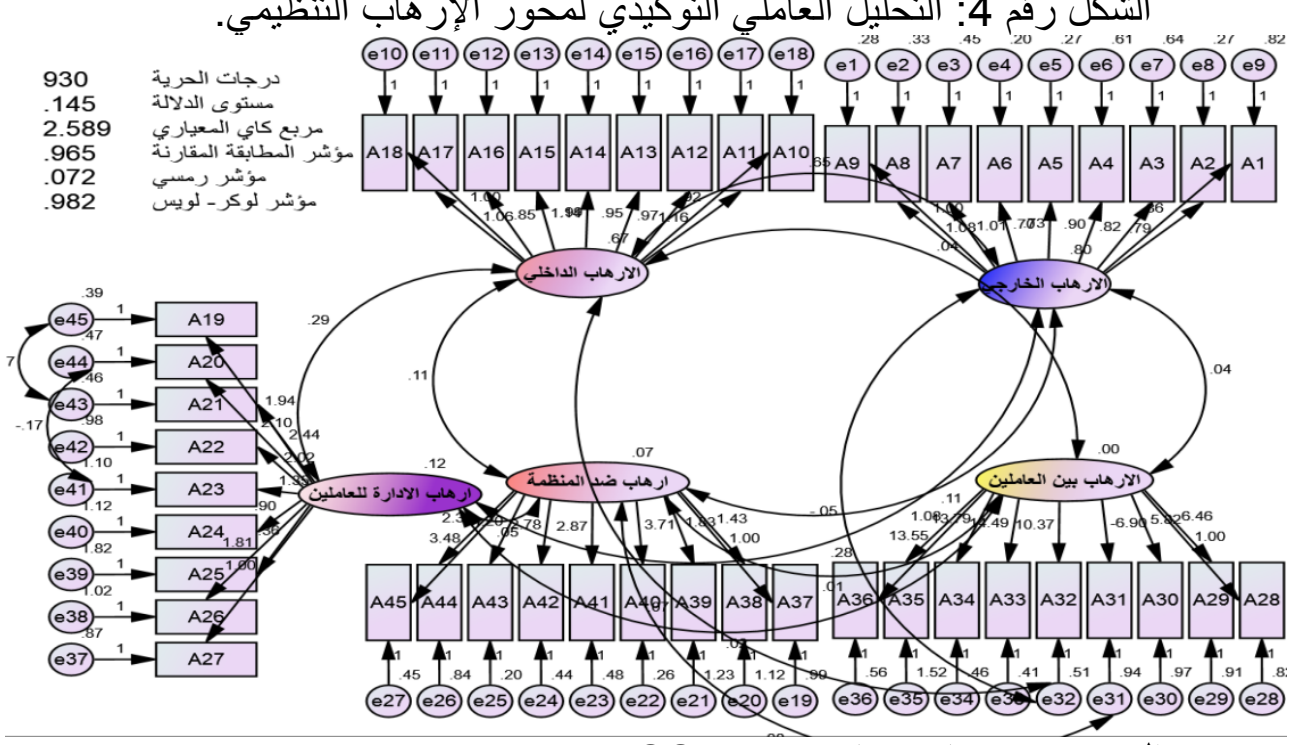

المصدر: مخرجات برنامج (AMOS V.24)

الثكل رقم 5: التحليل العاملي التوكيدي لمحور الاحتر اق الوظيفي. 


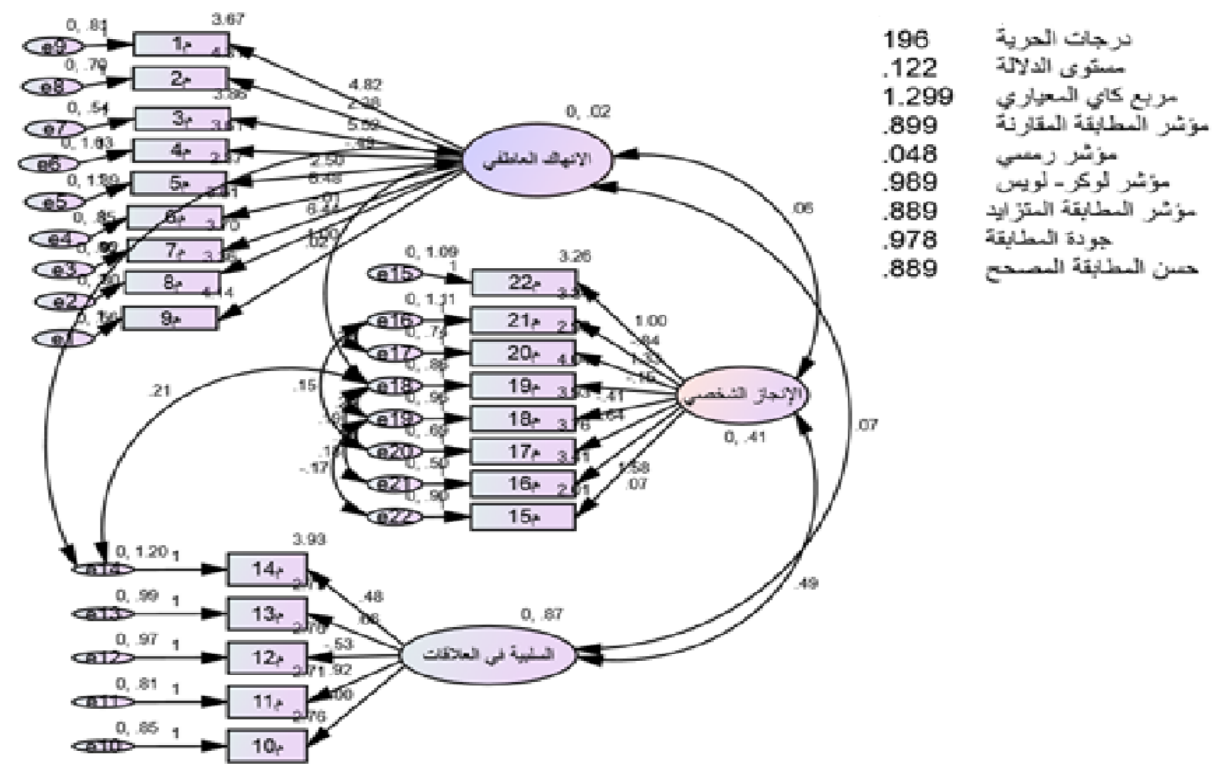

المصدر: مخرجات برمجية24

الثكل رقم 6: التحليل العاملي التوكيدي لمحور الروح المعنوية. 


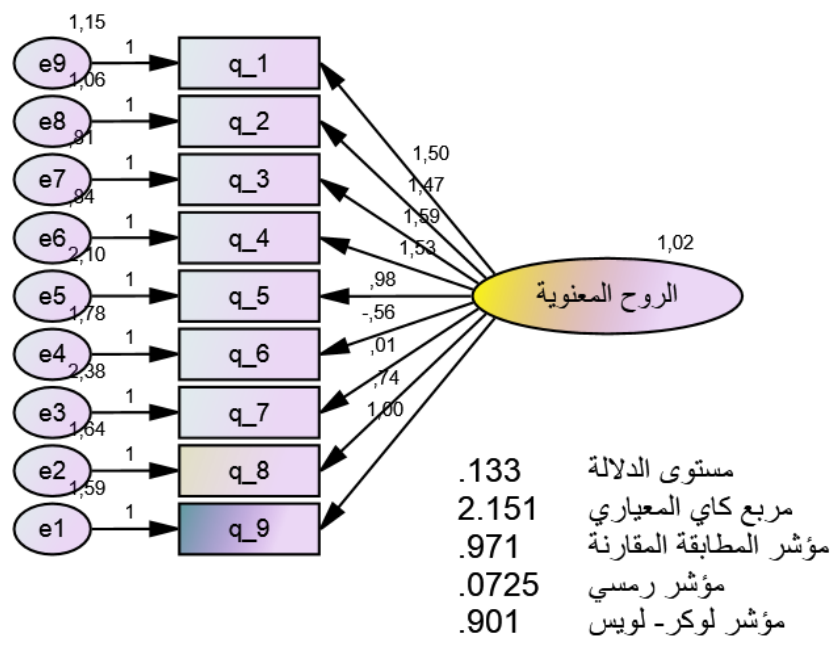

\section{AMOS V.24 المصدر: مخرجات برنامج المورة}

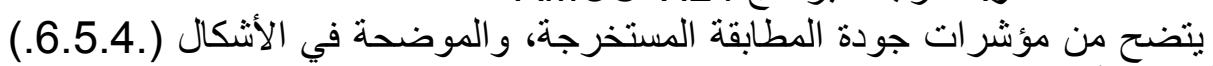

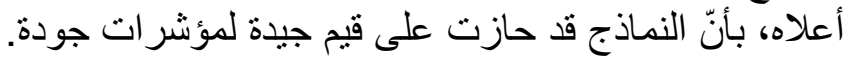

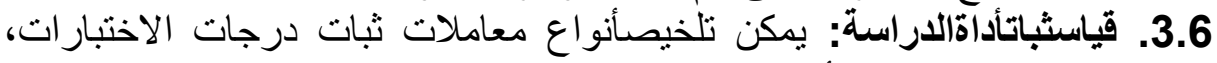

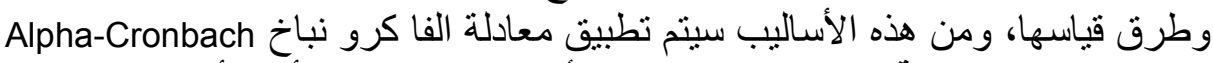

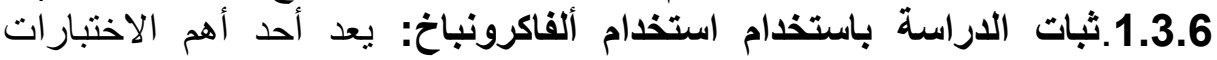

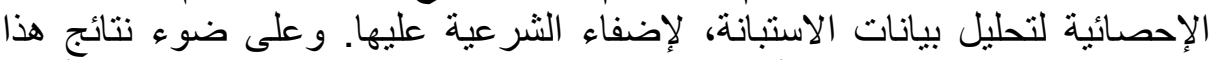
الاختبار يتم تعديل الاستبانة أو قبولها. ويستخدم هذا الاختبار فيما لإنا إذانة كانت أسئلة

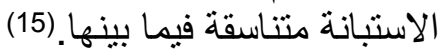
يحسب من المعادلة:K ${ }_{\alpha=\frac{k}{k-1}}\left[1-\frac{\sum s^{2}{ }^{2}}{s_{i}}\right]$ عدد مفردات الاختبار؛ ( تباين درجات كل مفردة من مفردات الاختبار؛ ( مفردات الاختبار . 
الجدول 4: معامل كرونباخ ألفا لقياس ثبات الاستمارة

\begin{tabular}{|c|c|c|}
\hline الفا كرونباخ & الابعاد & المتغيرات \\
\hline .785 & الإرهاب الخارجي & \multirow{6}{*}{ الإرهاب التنظيمي } \\
\hline .771 & الإر هاب الداخلي . & \\
\hline .794 & إرهاب الإدارة للعاملين & \\
\hline .886 & الإر هاب بين العاملين & \\
\hline .709 & إرهاب ضد المنظمة & \\
\hline .865 & مجموع العبارات للمحور الأول & \\
\hline .792 & الانهاك العاطفي & \multirow[t]{4}{*}{ الاحتراق الوظيفي } \\
\hline .773 & الإنجاز الشخصي & \\
\hline .801 & السلبية في العلافات & \\
\hline .813 & مجموع العبارات للمحور الثاني & \\
\hline .681 & & الروح المعنوية \\
\hline .801 & & المجموع الكلي للاستمارة \\
\hline
\end{tabular}

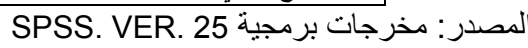

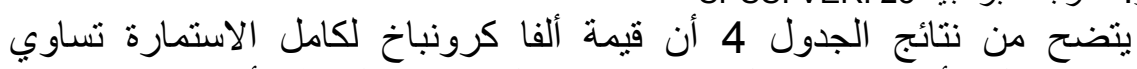

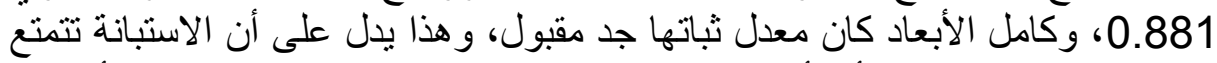

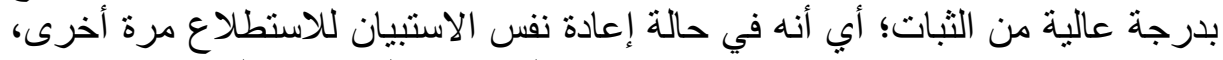

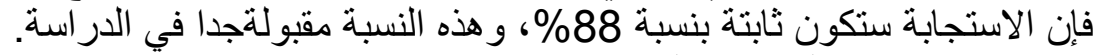

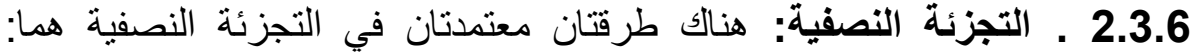

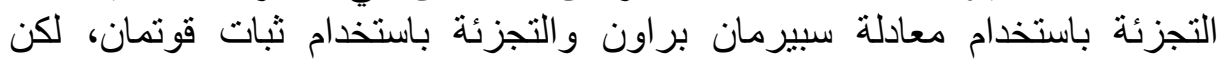

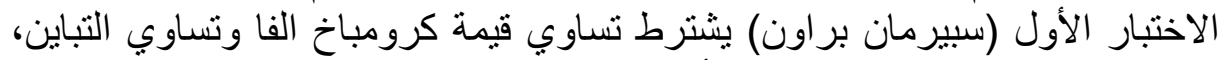

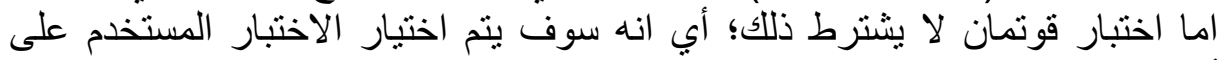
أساس نتائج الدر اسة أنة

تعتمد طريقة التجزئة النصفية على تجزئة الاستبيان إلى نصفين، ومن ثم إيجاد معامل

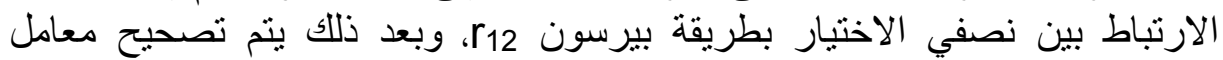

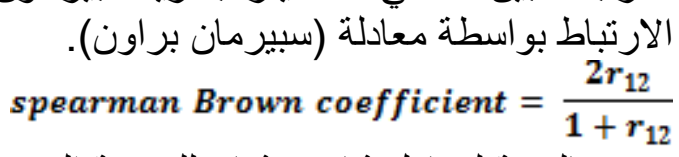

وبالنسبة لمعامل ثبات جثمان للتجزئة النصفية، فهو لا يتطلب أن يكون التباين فيها

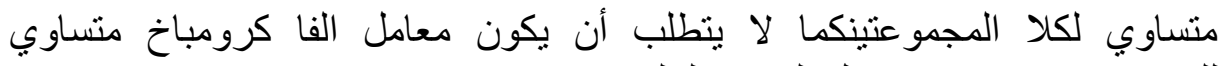
للنصفين، ويحسب من خلال القانون التالي: Guttman formula $=2\left(1-\frac{\sigma_{1}^{2}+\sigma_{2}^{2}}{\sigma^{2}}\right)$

وباستخدام برمجية وبرتجزئة العبارات الخاصة بالدراسة إلى قسمين

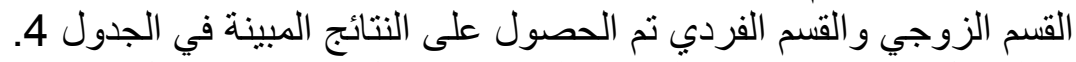

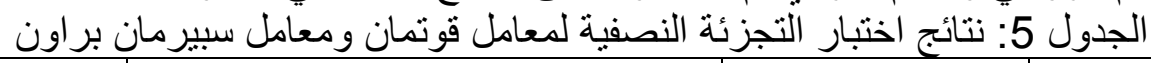

\begin{tabular}{|c|c|c|c|}
\hline 878 & معامل ألفا كرونباخ للقسم الأول & \multirow{2}{*}{ للعبارت القسم الأول } & \multirow{5}{*}{ كعرأ } \\
\hline $38 \mathrm{a}$ & عدد العبارات & & \\
\hline 836 & معامل ألفا كرونباخ للقسم الثاني & \multirow{2}{*}{ اللعبارات } & \\
\hline $38 b$ & عدد العبارات & & \\
\hline 76 & \multicolumn{2}{|c|}{ العدد الإجمالي للعبارات } & \\
\hline
\end{tabular}


الروح المعنوية كتنغير وسيط في العلاقة التأثيرية لأبعاد الإرهاب التنظبي على الاحتراق الوظبفي

\begin{tabular}{|c|c|c|c|c|}
\hline .743 & \multicolumn{4}{|c|}{ الارتباط بين القسم الأول والثاني } \\
\hline .852 & & & & \multirow{2}{*}{ سبراون } \\
\hline .852 & & & & \\
\hline .849 & \multicolumn{4}{|c|}{ معامل قوتمان } \\
\hline 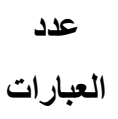 & 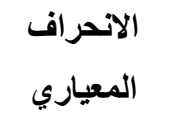 & التباين & المتوسط & \\
\hline $38 \mathbf{a}$ & 15.19839 & 230.991 & 87.4852 & القأول \\
\hline $38 b$ & 13.58979 & 184.682 & 85.3504 & الثناني \\
\hline 76 & 26.87745 & 722.397 & 172.8356 & 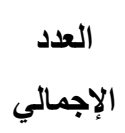 \\
\hline \multicolumn{5}{|c|}{ 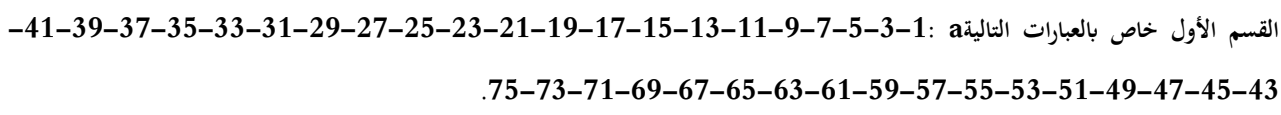 } \\
\hline \multicolumn{5}{|c|}{ 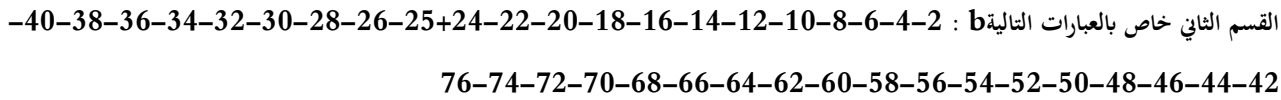 } \\
\hline
\end{tabular}

SPSS. VER. المصدر: مخرجات برمجية 25 المبية

من خلال النتائج المبينة في الجدول 5 يتبين أن قيمة التباين وقيمة الفا

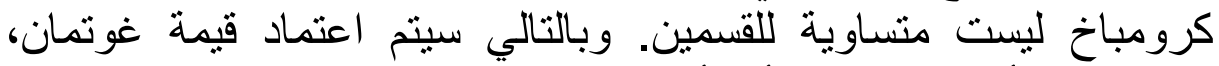

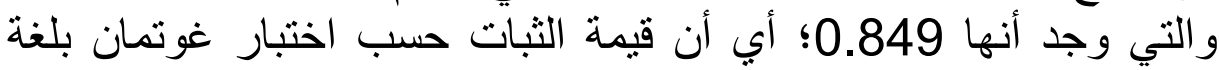
84 بالمائة وهي مقبولة جدا. 7. التحليل الوصفي لمتغيرات الداراسة (الإجابة على أسئلة الدراسة):

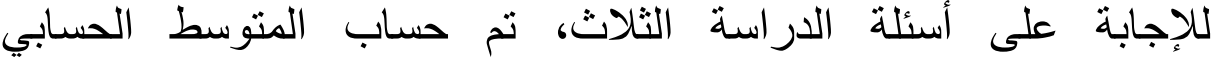

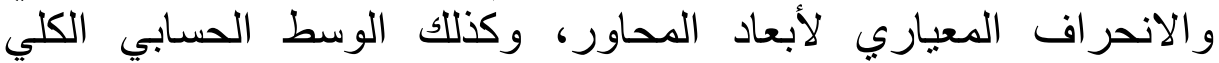
و الانحر اف المعياري الكلي للمحاور ، و الجدول 6 يوضح النحاد النتائج. 


\begin{tabular}{|c|c|c|c|c|}
\hline الاجابة & المعياري & الحستوسي & الابعاد & المتغيرات \\
\hline 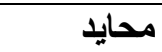 & .725 & 3.22 & الإرهاب الخارجي & \multirow{5}{*}{ التارهيمي } \\
\hline موافق & .681 & 3.81 & الإرهاب الداخلي & \\
\hline موافق & .601 & 4.15 & إر هاب الإدارة للعاملين & \\
\hline بشوافق & .552 & 4.38 & الإرهاب بين العاملين & \\
\hline غير موافق & .782 & 2.01 & إرهاب ضد المنظمة & \\
\hline موافق & .802 & 3.89 & الانهاك العاطفي & \multirow{3}{*}{ الوظيفي } \\
\hline موافق & .901 & 3.92 & الإنجاز الثخصي & \\
\hline موافق & .723 & 4.01 & السلبية في العلاقات & \\
\hline غير موافق & .552 & 2.02 & \multicolumn{2}{|c|}{ الروح المعنوية } \\
\hline
\end{tabular}

من خلال النتائج المبينة في الجدول 6 نلاحظ أن أغلب أبعاد العاد الإرهاب التنظيمي

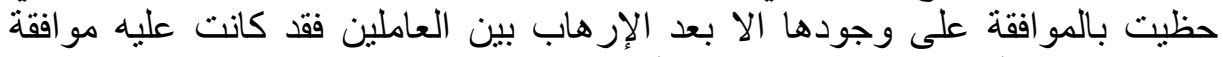

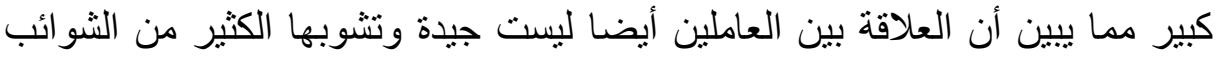

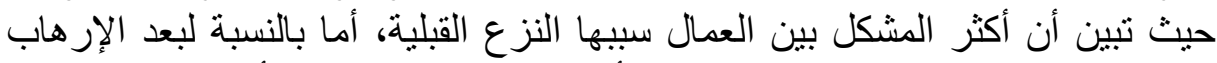

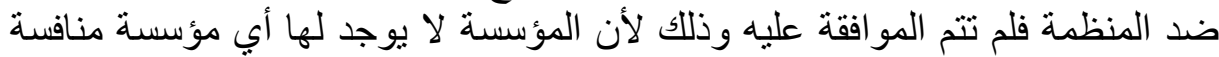

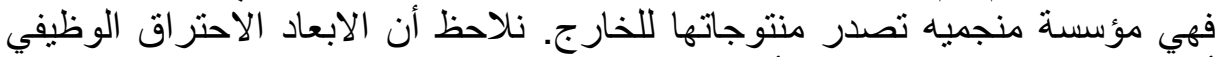

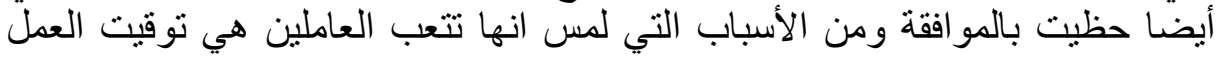

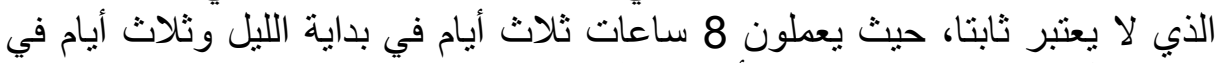

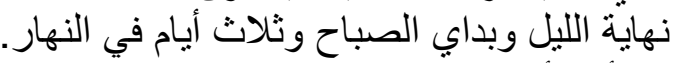

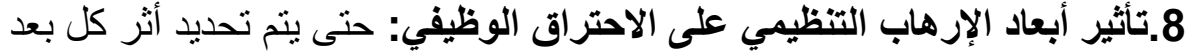

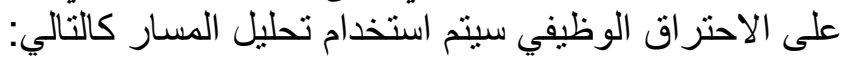

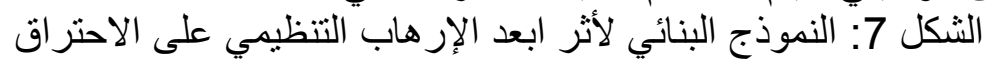
الوظيفي
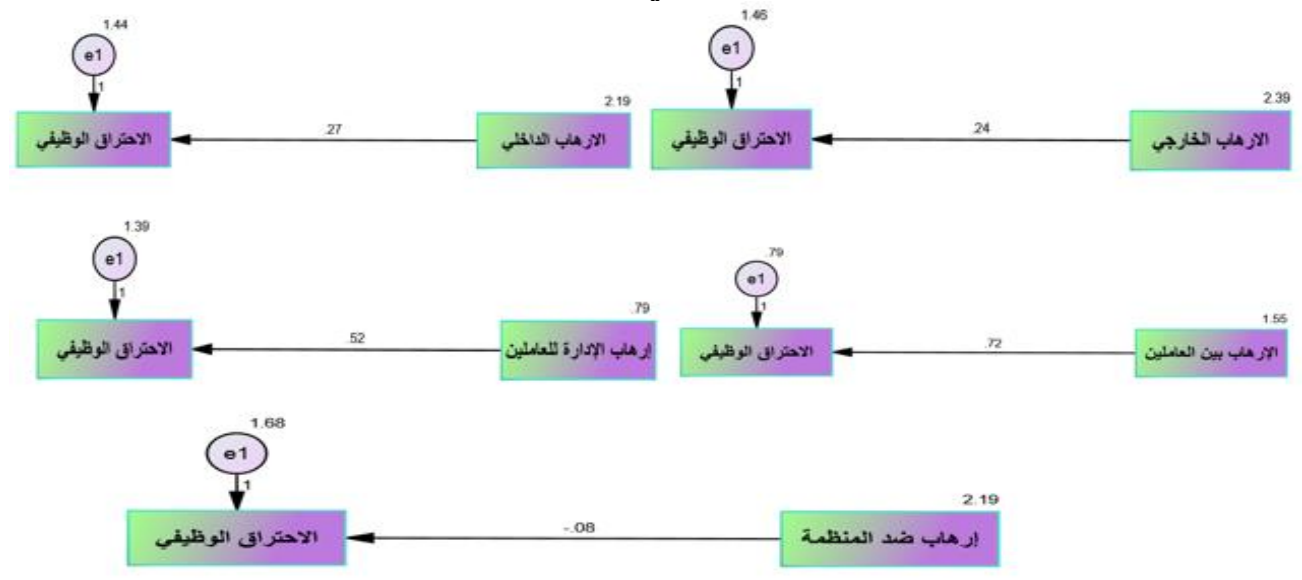

AMOS V.24 المصدر: مخرجات برنامج

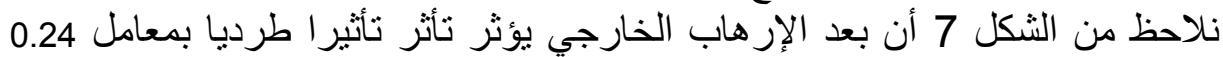

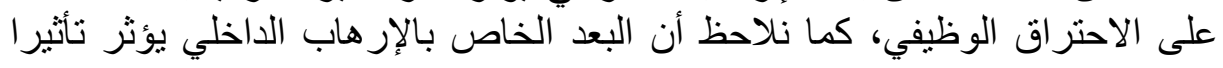


طرديا بمعامل 0.27، أي أن كلما ارتفع الإرهاب الداخلي أثر في الاحتراق الوظيفي بنسبة 27 بالمائة. نلاحظ أن إر هاب الإدارة للعاملين يؤثر تأثثير الطرديا بمعامل 0.52 و هو تأثير كبير

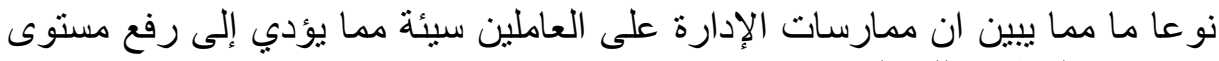
الاحتر اق الوظيفي للعاملين.

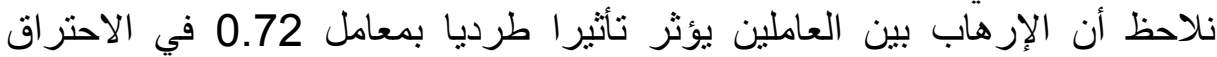

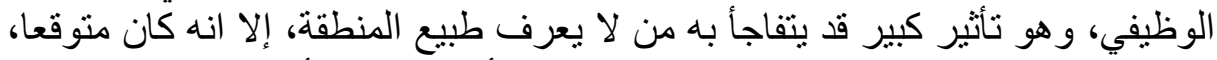

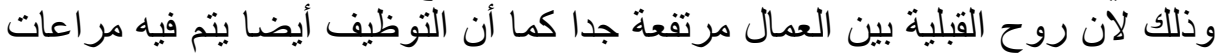

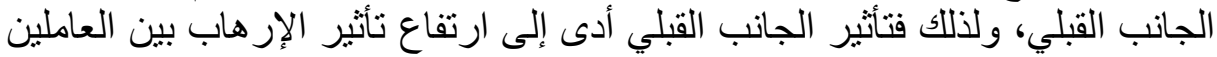

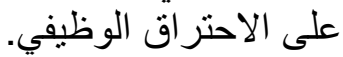
نلاحظ أن بعد الإرهاب الوظي ضد المنظمة له تأثثر عكسي جد ضعيف على الاحتراق

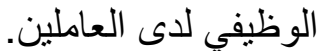
للتأكد من صلاحية التقدير لابد من حساب مؤشر ات النموذج و هي موضحة في

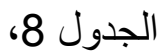
الجدول (8): نتائج تقدير علاقات التأثير بين أبعاد الارهاب التنظيمي على الاحتر اق الوظيفي

\begin{tabular}{|c|c|c|c|c|c|}
\hline & $\begin{array}{l}\text { Estimat } \\
\text { e }\end{array}$ & S.E. & C.R. & $\mathbf{P}$ & Label \\
\hline ال الإرهاب الخارجي & 2.390 & 176 & 13.601 & *** & \\
\hline الإرهاب الخارجي ---> الاحتراق الوظيفي & .240 & .041 & 5.894 & *** & \\
\hline الإرهاب الداخلي & 2.188 & 161 & 13.601 & *** & \\
\hline الإرهاب الداخلى ---> الاحتراق الوظيفي & .265 & .042 & 6.283 & *** & \\
\hline إرهاب الإدارة للعاملين & .794 & .058 & 13.601 & $* * *$ & \\
\hline إرهاب الإدارة للعاملين---> الاحتراق الوظيفي & .517 & .069 & 7.524 & *** & \\
\hline الإرهاب بين العاملين & 1.550 & 114 & 13.601 & *** & \\
\hline الإرهاب بين العاملين ---> الاحتراق الوظيفي & .721 & .037 & 19.418 & *** & \\
\hline الإرهاب ضد المنظمة & 1.679 & .123 & 13.601 & *** & \\
\hline الإرهاب ضد المنظمة.--> الاحتراق الوظيفي & -.085 & 046 & -1.864 & .062 & \\
\hline
\end{tabular}
المصدر: مخرجات برمجية (AMOS, V.24) من خلال نتائج التقدير نلاحظ أن القيمة الاحتمالية أقل من

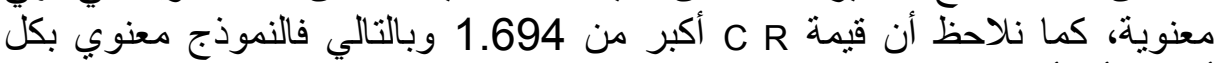

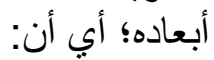

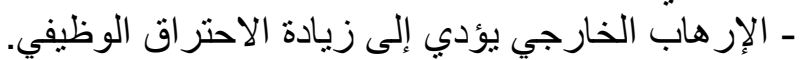

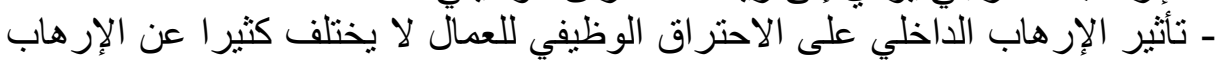

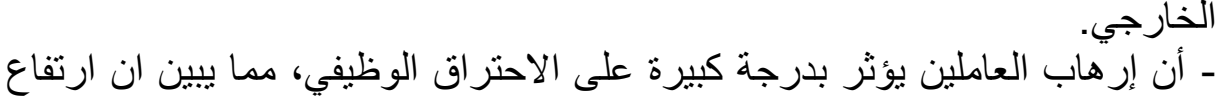

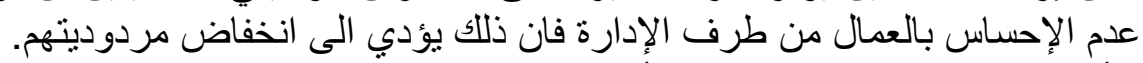

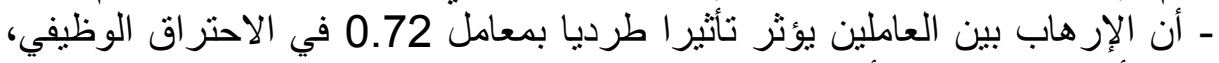

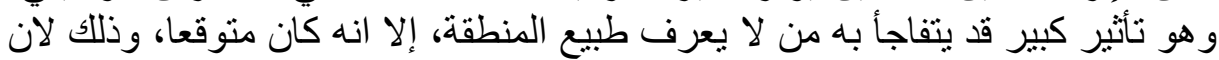

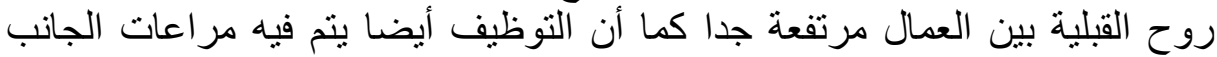

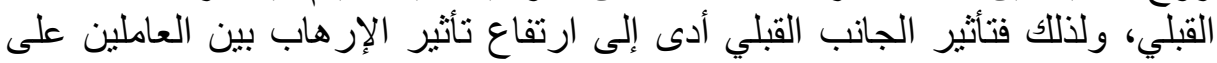

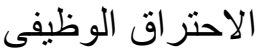

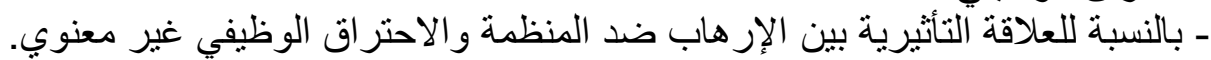

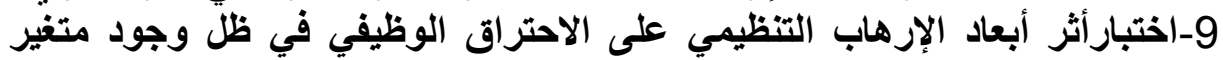

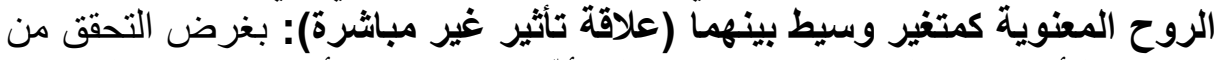

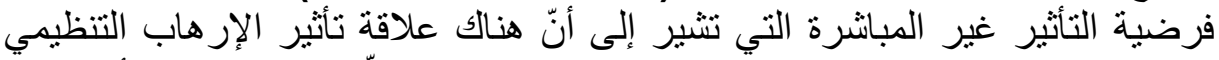

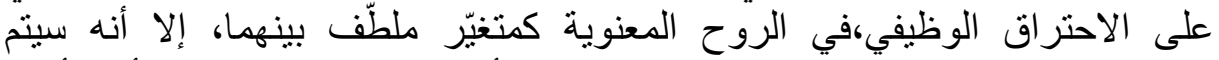

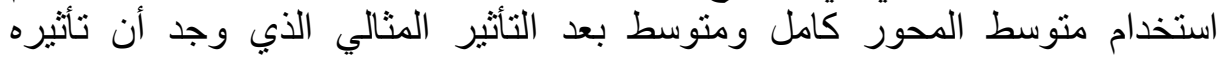




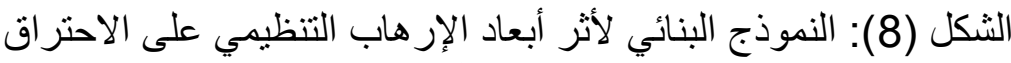

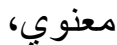

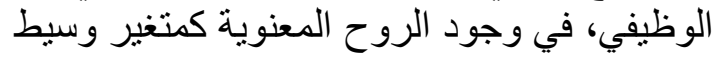
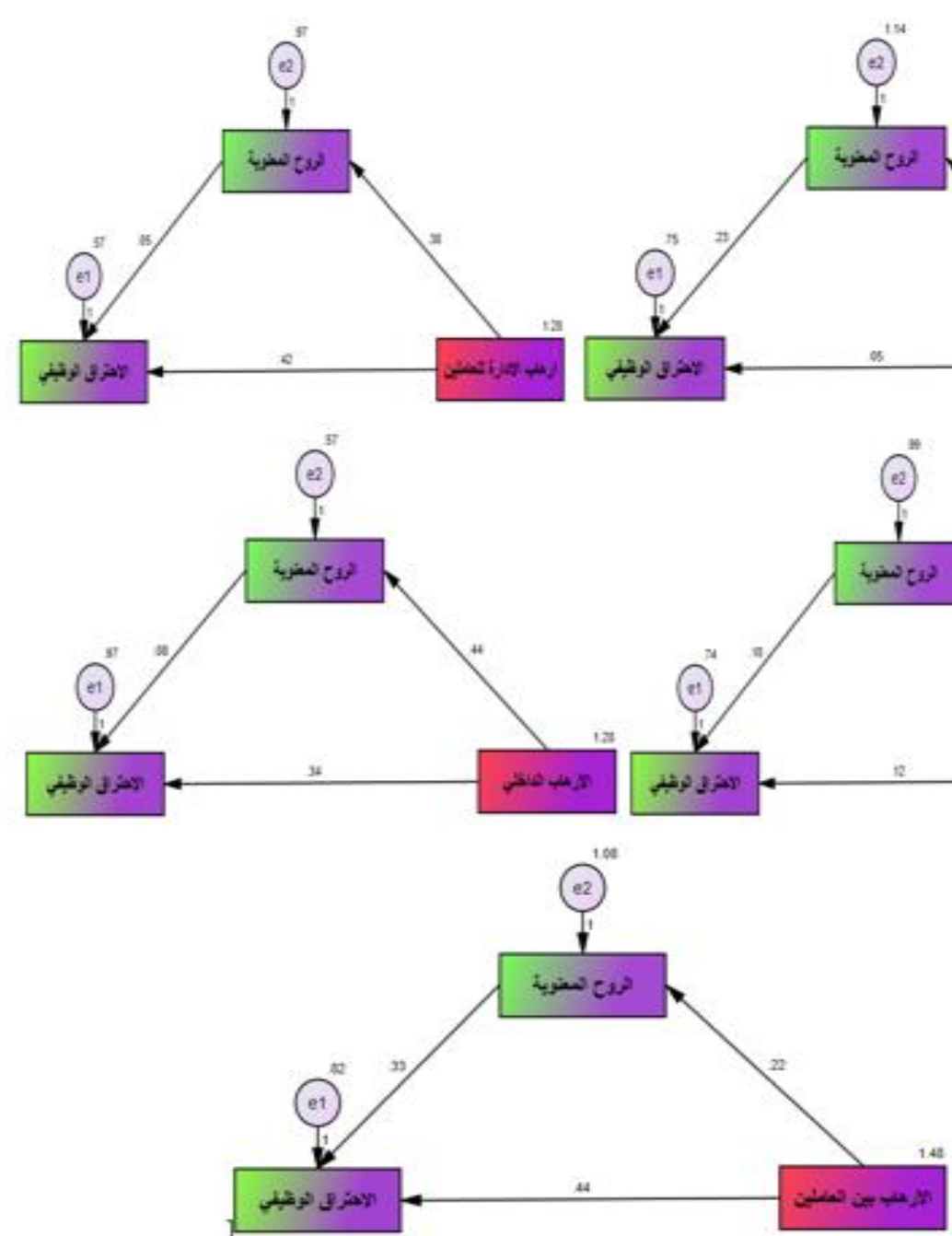

المصدر : مخرجات برمجية (AMOS, V.24)

للتأكد من صلاحية التقدير لابد من حساب مؤشر ات النموذج وهي موضحة في الجدول 
الجدول (9): نتائج تقدير علاقات التأثير بين أبعاد الارهاب التنظيمي على الاحتراق

الوظيفي في ظل وجود المتغير الوسيط (الروح المعنوية)

\begin{tabular}{|c|c|c|c|c|c|c|c|}
\hline & & & Estimate & S.E. & C.R. & $\mathrm{P}$ & Label \\
\hline الروح المعنوية & $<--$ & $\begin{array}{l}\text { الإردارة } \\
\text { العاملين }\end{array}$ & .377 & .105 & 3.595 & $\star \star * \star *$ & \\
\hline الاحتراق الوظيفي & $<---$ & المعنوية & .049 & .092 & .537 & .591 & \\
\hline الاحتراق الوظيفي & $<--$ & العالإدارة & .420 & .087 & 4.804 & 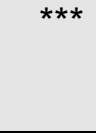 & \\
\hline الاحتراق الوظيفي & $<--$ & 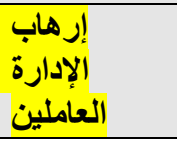 & .517 & .069 & 7.524 & $* * *$ & \\
\hline الروح المغنوية & <--- & الإرهاب ضندم & -.081 & .126 & -.638 & .523 & \\
\hline الاحتراق الوظيفي & $<--$ & المعنوية & .229 & .098 & 2.343 & .019 & \\
\hline الاحتراق الوظيفي & <--- & الإرهاب ضذة & .053 & .103 & .512 & .609 & \\
\hline الاحتراق الوظيفي & $<--$ & الإرهاب ضابمة & -.085 & .046 & -1.864 & .062 & \\
\hline الروح المعنوية & $<--$ & الإخاخلي & .439 & .080 & 5.456 & $* * *$ & \\
\hline الاحتراق الوظيفي & <--- & المعنويةً & .084 & .157 & .537 & .591 & \\
\hline الاحتراق الوظيفي & $<--$ & الإخلاب & .340 & .125 & 2.716 & .007 & \\
\hline الاحتر اق الوظيفي & $<--$ & الإخاخلي & .265 & .042 & 6.283 & $* * *$ & \\
\hline الروح المعنوية & $<--$ & الإرهاب & .326 & .099 & 3.295 & $\star \star \star *$ & \\
\hline الاحتراق الوظيفي & <--- & المعنوية & .177 & .104 & 1.700 & .089 & \\
\hline الاحتراق الوظيفي & <--- & الخارجي & .117 & .092 & 1.271 & .204 & \\
\hline الاحتراق الوظيفي & $<--$ & الخارجي & .240 & .041 & 5.894 & *** & \\
\hline الروح المعنوية & $<--$ & الإرهاب بين العاملين & .217 & .103 & 2.106 & .035 & \\
\hline الاحتراق الوظيفي & $<--$ & المغويةج & .329 & .105 & 3.145 & .002 & \\
\hline الاحتراق الوظيفي & $<--$ & الإرهاب بين العاملين & .437 & .092 & 4.732 & $\star * \star *$ & \\
\hline الاحتراق الوظيفي & $<--$ & الإرهاب بين العاملين & .721 & .037 & 19.418 & $* * *$ & \\
\hline
\end{tabular}

AMOS, V.24 المصدر: مخرجات برمجية 
- - نلاحظ أن المتغير الوسيط (الروح المعنوية) قد خفض بدرجة ضعيفة تأثير إرهاب الإدارة للعاملين على الاحتراق الوانير الوظيفي من 0.5170 .420 إلى 0.420

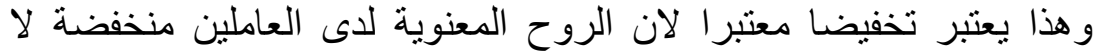
يخيم عليها التفاؤل.

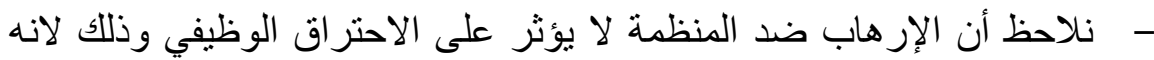

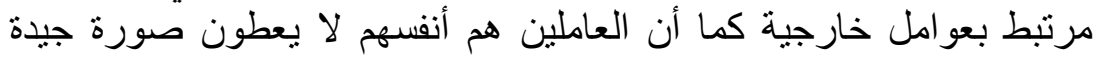

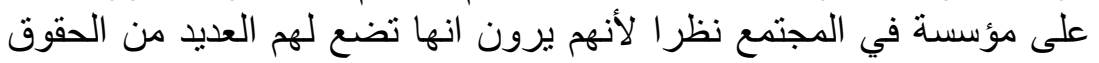

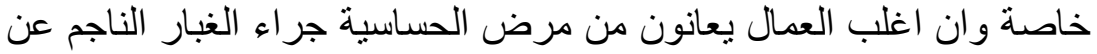
المنجم، لذلك لم يؤثر المتغير الوسيط على العلاقة.

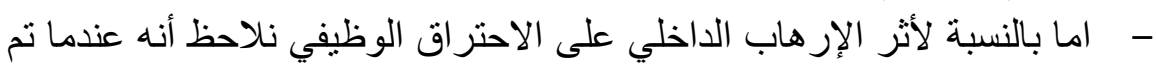

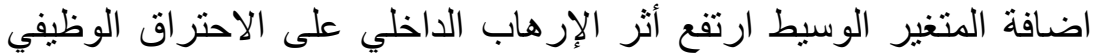

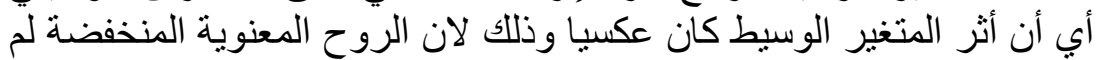
تؤُثر إيجابا.

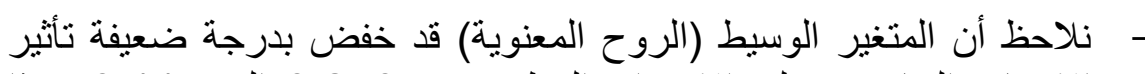
الإرهاب الخارجي على الاحتراق الوظيفي من يعتبر تخفيضا معتبر الان الروان الإن المعنوية لاى العاملين منخفضة لا يخيم عليها التفاؤل. - مان. - - نلاحظ أنه بالنسبة لمتغير الروح المعنوية قد خفض بدرجة معتبرة تأثير

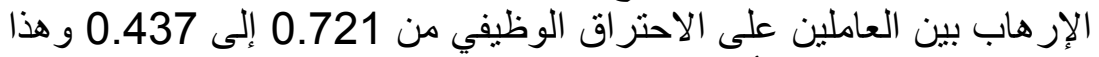

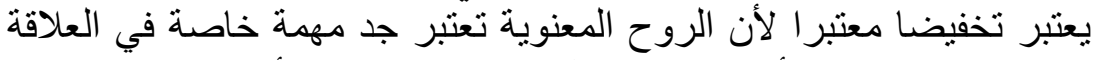

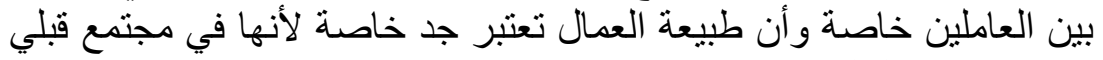
تسوده الروح القبلية.

ت تالثا:خاتمة

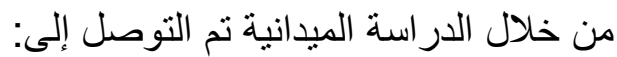

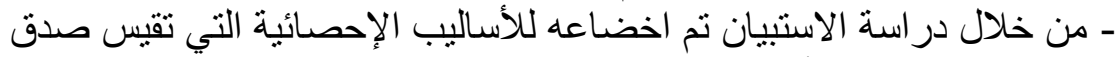

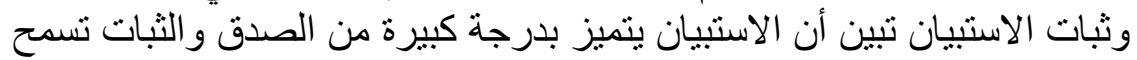

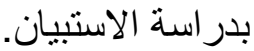
ـ أدت ظاهرة القبلية العرقية الى رفع الإر هاب بين العاملين.

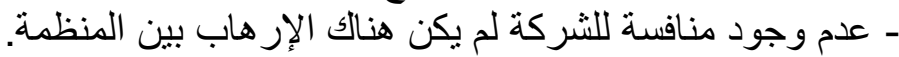

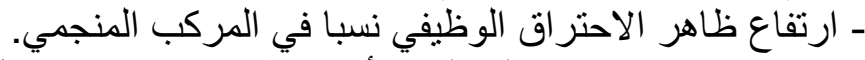

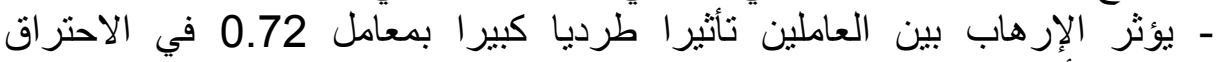

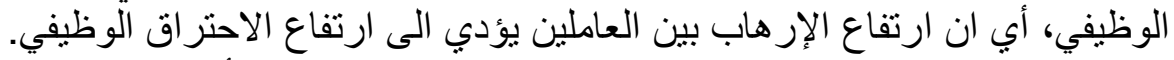

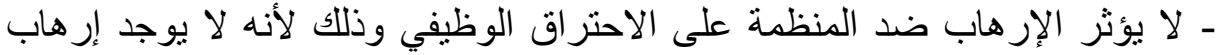
ضد المؤسسة باعتبار ها الوحيدة. - انخفاض الروح المعنوية لدى العاملين ربما يعود ذلك الى عدم تفاؤل من طرف

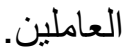
- إضافة الروح المعنوية كمتغير وسيط لم يؤثر تأثثير اكبير ا على أثر ابعاد الإرهاب التنظيمي على الاحتر اق الوظيفي. 
الروح الدعنوية كمتغبر وسبط في العلافة التأثبرية لأبعاد الإرهاب التنظبي على الاحتراق الوظيفي

(1)-https://www.almaany.com/ar/dict/ar-ar 01/02/2018

قائمة المراجع

(2)- علي جاسم محمد: المقاومة والارهاب في القانون الدولي، مجلة كلية الر افدين الجامعة، العدد

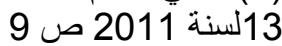

(3)- Reich, W.: 1998, Origins of Terrorism: Psychologies, Ideologies, Theologies, State of Mind (Woodrow Wilson International Center for Scholars, Washington, DC).p.3.

(4)-Ipid, p.2.

(5)- Cam Caldwell: "Organizational Terrorism" and Moral Choices -

Exercising Voice When the Leader is the Problem, Journal of Business Ethics (2010) 97, p.160.

(1)- مؤيد يوسف الساعدي ونداء صالح الثاهين: بناء مقياس الإرهاب التنظيمي في منظمات التعليم

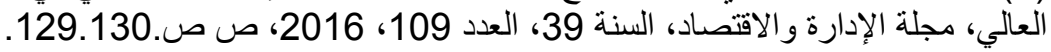

(7)-http://library.iugaza.edu.ps/thesis/92427.pdf2018/01/11

(8)-https://al-ain.com/article/1401712018/02/20

(9)http://www.gulfkids.com/ar/index. php?action=show art\&ArtCat=3\&id=84 02018/02/20

(10)-Adams, J. S. Towards an understanding of inequity. The Journal of Abnormal and Social Psychology, 67(5), 1963, p422

(11)https://www.researchgate.net/publication/325848283 athr alaman alw zyfy ly slwkyat almwatnt altnzymyt Ilamlyn fy shrkat alsyaht almsryt alr wh almnwyt kmtghyr wsyt 10/01/2018

(12)-نايف علي عاصي: الروح المعنوية للعاملين و الإنتاجية در اسة ميدانية في- الثركة العامة

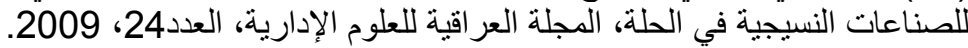

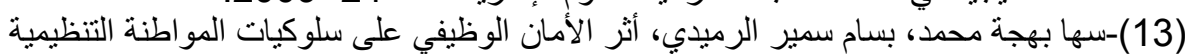

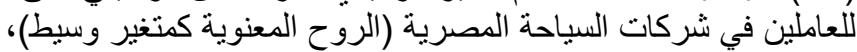

(14)-Fergson, George ( 1981 ) , Statistic and Lysisin Psychology and Education, Mc Graw Hill, N.Y. 1981, P.104.

(15)-محمود مهدي البياتي: تحليل البيانات الإحصائية باستخدام برنامج SPSS، عمان، دار حامد

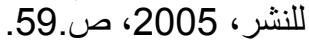

